OPEN ACCESS

Edited by:

Florence Evelyne Perrin, Université de Montpellier, France

Reviewed by:

Antón Barreiro-lglesias, University of Santiago

de Compostela, Spain Jennifer R. Morgan, Marine Biological Laboratory, United States

${ }^{*}$ Correspondence: Michael E. Selzer

michael.selzer@temple.edu

Specialty section

This article was submitted to Neurodegeneration,

a section of the journal

Frontiers in Neuroscience

Received: 06 July 2020

Accepted: 16 October 2020

Published: 05 November 2020

Citation:

Jin L-Q, John BH, Hu J and Selzer ME (2020) Activated Erk Is an Early Retrograde Signal After Spinal

Cord Injury in the Lamprey.

Front. Neurosci. 14:580692.

doi: 10.3389/fnins.2020.580692

\section{Activated Erk Is an Early Retrograde Signal After Spinal Cord Injury in the Lamprey}

\author{
Li-Qing Jin ${ }^{1}$, Brittany H. John ${ }^{1}$, Jianli Hu and Michael E. Selzer ${ }^{1,2 *}$ \\ ${ }^{1}$ Shriners Hospitals Pediatric Research Center, Lewis Katz School of Medicine, Temple University, Philadelphia, PA, \\ United States, ${ }^{2}$ Department of Neurology, Lewis Katz School of Medicine, Temple University, Philadelphia, PA, United States
}

We previously reported that spinal cord transection (TX) in the lamprey causes mRNA to accumulate in the injured tips of large reticulospinal (RS) axons. We sought to determine whether this mRNA accumulation results from phosphorylation and transport of retrograde signals, similar to what has been reported in mammalian peripheral nerve. Extracellular signal-regulated protein kinase (Erk), mediates the neurite outgrowthpromoting effects of many neurotrophic factors. To assess the role of Erk in retrograde signaling of RS axon injury, we used immunoblot and immunohistochemistry to determine the changes in phosphorylated Erk ( $p$-Erk) in the spinal cord after spinal cord TX. Immunostaining for $\mathrm{p}$-Erk increased within axons and local cell bodies, most heavily within the 1-2 mm closest to the TX site, at between 3 and $6 \mathrm{~h}$ post-TX. In axons, p-Erk was concentrated in 3-5 $\mu \mathrm{m}$ granules that became less numerous with distance from the TX. The retrograde molecular motor dynein colocalized with $p$-Erk, but vimentin, which in peripheral nerve was reported to participate with p-Erk as part of a retrograde signal complex, did not colocalize with p-Erk, even though vimentin levels were elevated post-TX. The results suggest that $p$-Erk, but not vimentin, may function as a retrograde axotomy signal in lamprey central nervous system neurons, and that this signal may induce transcription of mRNA, which is then transported down the axon to its injured tip.

Keywords: spinal cord injury, axon, retrograde signal, Erk, c-Jun, dynein, vimentin

\section{INTRODUCTION}

Cells have evolved signaling systems that identify environmental challenges, and relay the information to the nucleus, where protective and regenerative genetic responses are initiated. Transcription factors typically are located close to the nucleus, but injury to an axon might require signals to be transported retrogradely for long distances to the nucleus, in order to elicit transcriptional programs (Ambron and Walters, 1996). The mitogen-activated protein kinase (MAPK) pathways have been implicated in neuronal responses to many extracellular stimuli, including peptide growth factors, cytokines, and axotomy. These signaling pathways regulate cellular responses, including proliferation, differentiation, survival, and death (Kim and Choi, 2010), through activation of transcription factors. The basic assembly of MAPK pathways is a three-component module composed of MAPK kinase (MKKK), MAPK kinase (MKK), and MAPK. 
Extracellular signal-regulated kinase (Erk), one of four conventional MAPKs (Cargnello and Roux, 2011), has been implicated as an initial signal of injury in neuronal apoptosis (Cheung and Slack, 2004), neurite outgrowth (Huang et al., 2017), and cell proliferation (Zhang and Liu, 2002). Upon injury in mammalian peripheral nerve, Erk is phosphorylated (p-Erk) in the axoplasm, and in some axons, has been reported to form a retrograde signal complex with a vimentin fragment and importin- $\beta$, and then trafficked retrogradely on dynein motors (Perlson et al., 2005). In some neurons, injury is signaled by other pathways (Rishal and Fainzilber, 2014). Unfortunately, the complexity of the central nervous system (CNS) in most vertebrates imposes significant constraints on extending knowledge about the responses of neurons to axon injury from peripheral nerve to the CNS in vivo. For example, mammalian models of spinal cord injury (SCI) rely largely on incomplete lesions, making it difficult to distinguish true axon regeneration from collateral sprouting by spared axons. The mechanisms underlying these two processes appear to be different, and molecular manipulations that increase sprouting may not affect regeneration (Lee et al., 2009). The responses of neurons to axotomy, e.g., retrograde neuronal death and axon regeneration, are typically studied in mice because of their advantages for genetic manipulation. But mice are so small that the distances of axon growth required to form synaptic relays that can mediate functional recovery might be within the sprouting range. It is likely that most of the molecular manipulations that have been reported to promote functional recovery in rodents actually enhanced sprouting, but may not have enhanced regeneration of injured axons (Lee et al., 2009). In order to get around these limitations, some laboratories have used nonmammalian species, such as the lamprey, a primitive vertebrate that shared a common ancestor with humans about 550 million years ago (Smith et al., 2013). Axons in the lamprey CNS can regenerate, but this is incomplete, both with regard to distance and to the probability that an individual neuron will survive axotomy and regenerate its axon; some neurons are very good regenerators and survivors, and other neurons not. Thus there is room for experimental manipulations to make regeneration and neuronal survival better or worse. Because of several other advantages, such as translucency of the CNS, the presence of large identified reticulospinal (RS) neurons, and the ability to study the CNS in isolated preparations, the lamprey has served as an important model to study spinal cord injury and axon regeneration (Rovainen, 1976; Selzer, 1978; McClellan, 1988; Jin et al., 2009, 2016; Lau et al., 2013; Hanslik et al., 2019). The giant Müller and Mauthner cells of the brainstem give rise to giant axons, ranging from 20 to $40 \mu \mathrm{m}$ in diameter. These course in stereotypic paths the length of the spinal cord (Rovainen, 1967), and can be readily impaled with sharp electrodes for physiological studies (Selzer, 1979; Cochilla and Alford, 1997; Photowala et al., 2005). The genome of the sea lamprey has been sequenced (Smith et al., 2013, 2018), although incompletely annotated, and contains homologs of almost all of the mammalian gene families, including many suspected of influencing axon regeneration (Shifman and Selzer, 2000a,b, 2006; Shifman et al., 2009; Jin et al., 2011; Lau et al., 2011; Zhang et al., 2014; Chen et al., 2015;
Herman et al., 2018). RNAseq of CNS after spinal cord TX in lampreys has suggested that many pro-regeneration mechanisms are evolutionarily conserved, e.g., the Wnt signaling pathway (Herman et al., 2018).

In the current study, we show that Erk is activated early at the injury site, and that p-Erk is translocated retrogradely in granules, colocalized with dynein but not vimentin. In mammals and most other tetrapods, there are two very similar Erk proteins, Erk1 and Erk2 (Boulton et al., 1991), which are products of two closely related genes. Because they have greatly overlapping functions and are recognized by most available anti-Erk antibodies, they are commonly referred to as Erk1/2. Thus far, only one Erk gene has been recognized in the (incompletely annotated) lamprey genomic library (Smith et al., 2013, 2018), and only one Erk protein has been detected (weakly) on Western blots of lamprey CNS (Buscà et al., 2015). We now verify the existence of only one lamprey Erk by browsing the gene in a recently assembled lamprey germline cell genome (Pmar_germline 1.0/petMar3) and probing lamprey CNS homogenates by immunoblot.

\section{MATERIALS AND METHODS}

\section{Animal and Spinal Cord Transection}

A total of 222 larval lampreys (Petromyzon marinus) 10$13 \mathrm{~cm}$ in length (4-5 years old and in a stable phase of neurological development) were purchased from Lamprey Services in Michigan, or gifted (100) by Dr. Nicholas Johnson of the USGS Great Lakes Science Center, and maintained with light cycle in fresh water tanks at $15^{\circ} \mathrm{C}$ until use. All animal procedures were performed with a protocol approved by the Temple University Institutional Animal Care and Use Committee (ACUP\#: 4609). Lampreys were anesthetized by immersion in saturated aqueous benzocaine for $5 \mathrm{~min}$ and pinned to a Sylgard (184 silcone elastomer, Dow Corning) plate filled with ice-cold lamprey Ringer (110 mM NaCl, $2.1 \mathrm{mM} \mathrm{KCl,} 2.6 \mathrm{mM} \mathrm{CaCl}_{2}$, $1.8 \mathrm{mM} \mathrm{MgCl}_{2}$, and $10 \mathrm{mM}$ Tris buffer; $\mathrm{pH}$ 7.4). The spinal cord was exposed via a dorsal incision and transected under direct microscopic vision with iridectomy scissors at the level of the 7 th gill unless otherwise specified. For most acute tests, animals were either untransected (controls) or kept on ice for $2 \mathrm{~h}$ after TX, exposed to air to facilitate clot formation. Thereafter, animals were returned to fresh water tanks at $4^{\circ} \mathrm{C}$ and sacrificed at 3 or $6 \mathrm{~h}$ post-TX, or allowed to recover at $4^{\circ} \mathrm{C}$ overnight.

\section{Cryostat Sectioning and Immunohistochemistry (IHC)}

To avoid injury signals generated during the isolation of tissues, all lampreys in control groups were killed instantly by freezing on a metal plate that was pre-cooled on dry ice. A length of body containing the brain and spinal cord rostral to the TX site was obtained by cutting the frozen tissue at the olfactory sac in the head and $1 \mathrm{~mm}$ below 7 th gill in the spinal cord. The head was separated from the spinal cord by a third cut at locations specified in section "Results." The frozen stumps were placed in stainless steel molds $(10 \times 10 \times 10 \mathrm{~mm}$, Simport Scientific $)$ filled with Optimal Cutting Temperature (OCT) medium. The 
orientation of the frozen tissue was adjusted to obtain transverse or coronal (horizontal) sections. The molds were placed directly on top of liquid nitrogen in a Dewar flask until the OCT became completely solid. Blocks were stored at $-80^{\circ} \mathrm{C}$ until sectioning. Cryosection was performed on a Leica CM1950 Cryostat with chamber temperature $-17^{\circ} \mathrm{C}$. The frozen blocks were placed in a cryochamber for $30 \mathrm{~min}$ to achieve uniform temperature before sectioning. The OCT-embedded specimens were cut serially at $15 \mu \mathrm{m}$ and mounted on glass slides. Slides were kept temporarily in a Styrofoam box filled with dry ice during sectioning, and then stored at $-80^{\circ} \mathrm{C}$ until use.

For IHC, slides were thawed and dried in a plastic box filled with Drierite desiccant (Drierite Co.) at $4^{\circ} \mathrm{C}$ for $15 \mathrm{~min}$, and then at room temperature for $30 \mathrm{~min}$. The tissue was fixed with ice-cold acetone for $2 \mathrm{~min}$ and washed with phosphatebuffered saline (PBS) twice for $30 \mathrm{~s}$. Non-specific binding was blocked with $4 \%$ fetal bovine serum (FBS, in PBS, pH 7.5) for $5 \mathrm{~min}$. Slides were incubated with various antibodies (Table 1) overnight at $4^{\circ} \mathrm{C}$. The next day, samples were washed in Trisbuffered saline solution (TBS, 0.1\% Tween 20 in PBS, pH 7.5) and blocked by normal animal serums depending on the origin of the secondary antibodies. For immunofluorescence, slides were incubated with either Alexa Fluor 488 donkey anti-mouse IgG polyclonal antibody or Alexa Fluor 594 donkey anti-rabbit IgG polyclonal antibody (Table 1) at 1:200 in blocking solution for 1 hour at room temperature. Finally, the specimens were washed twice with TBS and mounted with DAPI FluoromountG (Southern Biotech, 0100-20). Images were captured using a Nikon Eclipse 80i epifluorescence microscope with a Roper Scientific CoolSNAP digital camera, under the control of NIS Elements software. Negative controls employed the same protocol, omitting the primary antibody. For chromogenic IHC, protocols recommended by Cell Signaling Technology were followed. It generates brown to gray-black colors.

\section{Molecular Cloning of the Lamprey Vimentin Full-Length Gene}

A cDNA fragment $(717 \mathrm{bp})$ by-product of PCR that was performed with the goal of cloning new NF proteins (Jin et al., 2011) was highly homologous to the vimentin genes of other species. Six primers were designed to clone the full length of this intermediate filament by PCR, using a lamprey UniZAP XR cDNA library as a template. This vimentin gene (Lvimentin) consists of 3380 nucleotide bp and has been deposited in GenBank (HQ171987).

\section{In situ Hybridization With Biotin-Labeled Riboprobes}

Hybridization of biotin-labeled riboprobes to paraffin sections of lamprey spinal cord was performed as reported previously (Swain et al., 1994). Briefly, the anesthetized lamprey was killed instantly on dry ice and fixed in $4 \%$ paraformaldehyde at room temperature overnight. The sample was washed in PBS, and a $7 \mathrm{~mm}$ length of lamprey body including the 7 th gill was isolated. This piece was dehydrated in serial ethanols, cleared in toluene, infiltrated with Paraplast, and embedded in paraffin. Transverse
$10 \mu \mathrm{m}$ paraffin sections were collected, deparaffinized, and rehydrated in xylene and serial ethanols.

\section{Vimentin Riboprobes \\ A T7-tagged cDNA fragment was obtained by PCR, using a pair of primers (primer A, 5'} TAAGCTTTAATACGACTCACTATAGGGAGAGGATTTTCT TGATTATGTTGG-3; primer B， 5'-CGTGTACAGCAAGAA GACTGTGCTCATCAAGACGATTGAGACG-3'), and a cloned lamprey vimentin cDNA as template. The primers cover nucleotides $1276-1696$ of the gene (421 bp), a region just after the stop codon. Another pair of primers (C, 5' TAAGCTTTAATACGACTCACTATAGGGAGACGTGTACAG CAAGAAGACTGTGC-3'; D, 5'-GGATTTTCTTGATTAT GTTGGTTGTGAGAATTCTTAAACTCACC-3') were used for PCR amplification of the same regions with a $\mathrm{T} 7$ tag on the other strand of gene. T7 RNA polymerase was used for sense or antisense probe synthesis. Digoxigenin-labeled riboprobes were synthesized in vitro, using an RNA transcription kit (Roche, Nutley, NJ, United States) as per the manufacturer's instructions.

Sectioned tissues were prehybridized at $55^{\circ} \mathrm{C}$ in hybridization solution (50\% deionized formamide, $5 \times \mathrm{SSC}, 100 \mathrm{pg} / \mathrm{ml}$ Torula yeast RNA, $100 \mathrm{pg} / \mathrm{ml}$ wheat germ tRNA, $50 \mathrm{pg} / \mathrm{ml}$ heparin, $0.1 \%$ Tween-20), followed by hybridization overnight at $55^{\circ} \mathrm{C}$ in the same solution plus $2 \mu \mathrm{g} / \mathrm{ml}$ digoxigenin-labeled cRNA. Specimens were washed in hybridization solution, PBS-Tween solution (PTw, 0.1\% Tween-20 in PBS), and PBS-FBS-Triton solution (PBT, $0.1 \%$ FBS, $0.2 \%$ Triton X-100 in PBS). An alkaline phosphatase-conjugated sheep anti-digoxygenin Fab fragment (1:1000) was applied to the slides for $3 \mathrm{~h}$ at room temperature. Specimens were washed sequentially in PBT and SodiumMagnesium-Tween solution (SMT, $100 \mathrm{mM} \mathrm{NaCl}, 50 \mathrm{mM} \mathrm{MgCl}_{2}$, 100 mM Tris, pH 9.5, 0.1\% Tween-20). The chromogenic reaction was carried out in ice-cold SMT containing $175 \mathrm{pg} / \mathrm{ml} \mathrm{5-}$ bromo-4-chloro-3-indolyl-phosphate and $350 \mathrm{pg} / \mathrm{ml}$ 4-nitro blue tetrazolium chloride for $1-2 \mathrm{~h}$ in the dark at room temperature. Finally, slides were washed in PBS, dehydrated in serial ethanols, cleared with xylene, and mounted under Permount (Thermo Fisher scientific). Stained samples were visualized on a Zeiss Axiovert 135 microscope using 10 or $20 \times$ dry objectives. Images were acquired using a Zeiss Hi Resolution color camera and software (Zeiss Axioskop).

\section{Western Blotting}

A, Vimentin. A total of 48 Petromyzon marinus specimens were anesthetized in saturated aqueous benzocaine, and their brains and spinal cords were dissected. Tissues were homogenized by Ultrasonic Processor (FB120, Thermo Fisher Scientific) in homogenization buffer consisting of $25 \mathrm{mM}$ HEPES ( $\mathrm{pH}$ 7.4), $100 \mathrm{mM}$ sucrose, $1 \mathrm{mM}$ EGTA, $0.2 \% \beta$-mercaptoethanol, $0.04 \mathrm{mM}$ PMSF, $50 \mu \mathrm{g} / \mathrm{ml}$ leupeptin, $25 \mu \mathrm{g} / \mathrm{ml}$ pepstatin A, and $0.01 \mathrm{U} / \mathrm{ml}$ soybean trypsin inhibitor. The homogenate was centrifuged at $800 \times g$ for $10 \mathrm{~min}$ at $4^{\circ} \mathrm{C}$. A first supernatant was collected and recentrifuged at $10,000 \times g$ for $15 \mathrm{~min}$. The second pellet was enriched in cytoskeleton, and used for vimentin assay. B, Erk and p-c-Jun, forty-eight brains and spinal cords were dissected and homogenized in RIPA buffer (Pierce) containing 
TABLE 1 | Primary and secondary antibodies.

\begin{tabular}{|c|c|c|c|c|}
\hline Name & Host species and antigen & Manufacturer & Dilution & RRID \\
\hline Anti-vimentin (clone V9) & Mouse mAb & Sigma-Aldrich & $1: 1,000$ (WB) 1:2,00 (IHC) & AB_477627 \\
\hline LCM16 (anti-NF180) & Mouse, lamprey CNS cytoskeletal protein & Author's lab & $1: 100(\mathrm{IHC})$ & AB_2861400 \\
\hline IRDye@800CW & Goat anti-mouse lgG & LI-COR & $1: 7,500$ (WB) & AB_621842 \\
\hline IRDye@680RD & Goat anti-rabbit IgG & LI-COR & $1: 7,500(\mathrm{WB})$ & AB_621841 \\
\hline $\begin{array}{l}\text { Phospho-p44/42 MAPK } \\
\text { (Erk1/2) (Thr202/Tyr204) }\end{array}$ & Rabbit mAb & Cell Signaling Technology & 1:1,000 (WB) 1:1,00 (IHC) & RRID: AB_2315112 \\
\hline $\begin{array}{l}\text { p44/42 MAP Kinase } \\
\text { (L34F12) }\end{array}$ & Mouse mAb & Cell Signaling Technology & 1:1,000 (WB) 1:1,00 (IHC) & AB_390780 \\
\hline Phospho-c-Jun (Ser63) II & Rabbit pAb & Cell Signaling Technology & $1: 1,000(\mathrm{WB})$ & AB_2130162 \\
\hline Anti-Dynein (clone 74.1) & Mouse mAb, 74 kDa Intermediate chains & Sigma Aldrich Incorporated & 1:1,000 (WB) 1:1,00 (IHC) & AB_2246059 \\
\hline Alexa Fluor 488 & Donkey anti-mouse lgG H\&L & Abcam Ltd. & $1: 2,00(\mathrm{IHC})$ & AB_2732856 \\
\hline Alexa Fluor 594 & Donkey anti-rabbit lgG & BioLegend & $1: 2,00(\mathrm{IHC})$ & AB_2563306 \\
\hline
\end{tabular}

20 mM Tris- $\mathrm{HCl}$ (pH 7.5), 150 mM NaCl, 1 mM Na 2 EDTA, $1 \mathrm{mM}$ EGTA, 1\% NP-40, 1\% sodium deoxycholate, $2.5 \mathrm{mM}$ sodium pyrophosphate, $1 \mathrm{mM} \beta$-glycerophosphate, $1 \mathrm{mM} \mathrm{Na} \mathrm{VO}_{4}$, and $1 \mu \mathrm{g} / \mathrm{ml}$ leupeptin, by sonication. Whole homogenate was collected and used for Western blotting. Protein concentrations were quantified by the Lowry method. Proteins (35 $\mu \mathrm{g}$ ) were separated in a $10 \%$ SDS mini-gel, and were electrophoretically transferred onto nitrocellulose membranes $(0.45 \mu \mathrm{m}$, Bio-Rad) using a Bio-Rad transblot apparatus. The membranes were blocked in Odyssey Blocking Buffer (LI-COR, 927-40000) for $2 \mathrm{~h}$ and incubated with antibodies (Table 1) overnight at $4^{\circ} \mathrm{C}$, followed by washing with PBS containing $0.2 \%$ Tween 20 (PBST), and incubation with the fluorescence labeled secondary antibody (Table 1) for $1 \mathrm{~h}$ at room temperature. The membranes were then rinsed in PBST and scanned by the Odyssey infrared imaging system (LI-COR Biosciences, Lincoln, NE, United States).

\section{Quantification and Statistical Analysis IHC}

Surrounding background and meningeal staining in spinal cord sections were removed by Adobe Photoshop (CS4). Quantification was performed using image analysis software Image J (1.52a). Image was converted to 8 bit format. Total area (TA, in pixels) was assessed after adjustment of low and high threshold so that whole spinal cord become completely dark. Stained area (SA) was quantitated after adjustment of high threshold to the point that the image is identical to the pattern of real staining. The high threshold value for control group was used for other groups. The ratio between SA and TA is defined as "percent intensity" for each image. This process was repeated twice for each section to ensure that the measurement was consistent.

\section{Western Blotting}

All quantifications were processed in ImageJ software as described (Gallo-Oller et al., 2018). Briefly, images were converted to 8-bit format in order to perform uncalibrated optical density (OD). After conversion, the background was subtracted through bright/contrast adjustment. Each band was individually selected and circumscribed with the rectangular ROI selection and "Gels" function, followed by quantification of peak area of obtained histograms. Data were acquired as arbitrary area values.

\section{Statistical Analysis}

All data are represented as the mean \pm standard deviation for all performed repetitions. Once normality and homogeneity of variance analysis were assessed, a parametric or non-parametric analysis was selected. Statistically significant differences among three or more groups were analyzed by one-way analysis of variance (ANOVA), followed by post hoc analysis of Tukey or Dunnett, respectively. Student's $t$-test was used for significant difference between 2 groups. Correlation analysis was performed using linear regression to get Pearson's $r$ coefficient. The significance level was set to $p<0.05$ and classified by asterisks as follows: $p<0.05\left(^{*}\right) ; p<0.01\left(^{* *}\right) ; p<0.001\left(^{* * *}\right)$. The statistical analysis was calculated through SigmaStat software for Windows (version 2.0). Sample numbers were indicated in individual legend.

\section{RESULTS}

\section{The Lamprey Lacks erk1 Genes}

In studying the involvement of Erk1/2 in retrograde signaling, a related question is whether there is only one Erk isoform in lamprey, as described previously (Buscà et al., 2015). A recent assembly of the lamprey genome has been reported (Smith et al., 2018). As compared with its earlier version (Smith et al., 2013), which was constructed from somatic tissues, the newly assembled lamprey genome is more complete because it was developed from germline cells, and will not undergo rearrangements during early embryogenesis, in which approximately $20 \%$ of the germline DNA is shed (Smith et al., 2009). Searching the lamprey genomic database (Pmar_germline1.0/petMar3) with "Erk" generated 8 lamprey EST sequences (ESTs) including CO544767, CO545630, CO547047, CO548040, CO548101, DW585863, EG025241, and FD719223. Three of them (CO548101, DW585863, and EG025241) have been removed in construction of a phylogenetic tree because of their short nucleotide and amino acid lengths (Table 2). Another lamprey EST, FD719223 was outside of the MAPK group, and turned out to be a MAPKK protein by 
TABLE 2 | DNA sequences selected in constructing an erk phylogenic tree.

\begin{tabular}{|c|c|c|c|}
\hline Name & Access No. & n.t. & AA length $(P / F)^{*}$ \\
\hline Erk1 (Homo sapiens) & NM_002746.3 & 1787 & $379(F)$ \\
\hline Erk1 (Bos taurus) & NM_001110018.1 & 2135 & $362(F)$ \\
\hline Erk1 (Oryctolagus cuniculus) & XM_008257945 & 1758 & $393(F)$ \\
\hline Erk1 (Mus musculus) & NM_011952.2 & 1772 & $380(F)$ \\
\hline Erk2 (Homo sapiens) & NM_002745.5 & 5881 & $360(F)$ \\
\hline Erk2 (Bos taurus) & NM_175793.2 & 1272 & $360(F)$ \\
\hline Erk2 (Gallus gallus) & XM_015275131.2 & 10028 & $368(F)$ \\
\hline Erk2 (Mus musculus) & NM_001357115.1 & 5094 & $358(F)$ \\
\hline p38 $\alpha$ (Petromyzon marinus) & XM_032969733.1 & 4017 & $359(F)$ \\
\hline EST1 (Petromyzon marinus) & CO544767 & 934 & $>310(\mathrm{P})$ \\
\hline EST2 (Petromyzon marinus) & C0545630 & 795 & $>262(\mathrm{P})$ \\
\hline EST3 (Petromyzon marinus) & CO547047 & 928 & $262(F)$ \\
\hline EST4 (Petromyzon marinus) & CO548040 & 823 & $242(F)$ \\
\hline EST5 (Petromyzon marinus) $x$ & C0548101 & 552 & $>58(\mathrm{P})$ \\
\hline EST6 (Petromyzon marinus) $\times$ & DW585863 & 211 & $>69(\mathrm{P})$ \\
\hline EST7 (Petromyzon marinus) $x$ & EG025241 & 478 & $69(F)$ \\
\hline EST8 (Petromyzon marinus) $\times$ & FD719223 & 736 & $>182(\mathrm{P})$ \\
\hline
\end{tabular}

$\times$ Sequence not used in the phylogenic tree (see Figure 1B). Only 13 of the sequences were used (See text for explanation). *F, full length (start codon and stop codon are included); P, partial length (either the start codon or the stop codon is not included).

BLAST searching of the NCBI database. Eight mammalian genes coding for ERK1 (NM_002746, NM_001110018, XM_008257945, and NM_011952) and ERK2 (NM_002745, NM_175793, XM_015275131, and NM_001357115) were obtained by searching the NCBI database ${ }^{1}$ with "Erk1," and "Erk2" (Table 2). Another lamprey gene coding for $\mathrm{p} 38 \alpha$ protein (XM_032969733) was used as an outgroup node for rooting the Erk tree (Cargnello and Roux, 2011). The most homogeneous region (158 aa) in 13 sequences is presented in Figure 1A, which covers Exon-2 $\sim$ Exon-5 regions. A phylogenetic tree was constructed from 11 full length and 2 partial length protein sequences (Table 2) by MEGA-X software (Kumar et al., 2018; Figure 1B). Four lamprey ESTs belong to the Erk2 clade. No lamprey sequence fell into the Erk1 category. Identity within mammalian Erk1 is $89.5-96.5 \%$, whereas within mammalian Erk2 it is $95.9-99.7 \%$. Identity between mammalian Erk1 and Erk2 is 78.6-85.4\%. Lamprey Erk2 and mammalian Erk2 were 54.6-68.8\% identical. These results indicate that the lamprey lacks Erk1 isoforms. This is consistent with the single band seen in Western blotting with antibodies that in mammals, recognize both Erk1 and Erk2. Therefore, in referring to the lamprey version of this protein, we use only the term "Erk."

\section{IHC in Transverse Sections of Transected Lamprey Spinal Cord}

Although the lamprey spinal cord is relatively simple, and translucent under a dissecting microscope, it is still difficult to monitor the transport of a labeled protein along spinal cord axons in the living animal. Thus, we resorted to immunofluorescence

${ }^{1}$ https://www.ncbi.nlm.nih.gov/ labeling and chromogenic immunohistochemistry at different locations and times, to deduce the movement of immunolabeled p-Erk inside the axon. Animals were killed in less than 1 min by instant freezing on a dry ice-chilled metal plate. This served to minimize any injury signals that might be generated in even control spinal cords within the first seconds to minutes of tissue trimming and fixation (Ambron and Walters, 1996).

\section{In Untransected Control Animals, p-Erk Content Is Sparse and Restricted to Cell Bodies}

A lamprey monoclonal antibody LCM16 was used to determine if an immunolabeled granule is intra-axonal. The antibody is one of 43 LCM series monoclonal antibodies, which were generated previously in this laboratory against cytoskeletal proteins of the lamprey nervous system (Merrick et al., 1995). On Western blots, it is a phosphorylation state-independent antibody against the lamprey neurofilament subunit NF180, and has been used previously in IHC studies (Jacobs et al., 1997; Zhang et al., 2005; Hanslik et al., 2019). Chromogenic IHC with LCM16 is seen in a transverse section of lamprey spinal cord in Figure 2A. The antibody is selective for axons, with very little staining in the neuronal cell bodies of the "gray matter," whose nuclei are counterstained with hematoxylin. Most of the giant axons that were mapped previously in serial transverse sections (Rovainen, 1982; Buchanan, 2001) can be recognized. Thus, this antibody was used to identify intra-axonal profiles, and distinguish them from other neuronal compartments. Chromogenic IHC labeling with an anti-p-Erk antibody [anti-p44/42 MAPK (Erk1/2), Cell Signaling Technology] in transverse sections of control lamprey spinal cord (Figure 2B) showed no staining in any of the giant axons, but some light staining was seen in the gray matter.

\section{Spinal Cord TX Increases p-Erk Labeling in Neurons and Glia Near the Injury}

Erk is rapidly phosphorylated in response to multiple stimuli. We measured Erk phosphorylation in cells of the gray matter along the lamprey spinal cord by fluorescence IHC. Animals had spinal cord TX at the level of the 7 th gill and survived for 0 (Ctrl), 3, 6, or $24 \mathrm{~h}$. Then their spinal cords were sampled by frozen sections at three locations - between the 6th and 7 th gill (6.5th gill), the 4th gill, and between the 1st and 2nd gill (1.5th gill), as illustrated in Figure 3B. The sections were immunolabeled with p-Erk primary and fluorescent secondary antibody. Spinal cord TX greatly increased fluorescence intensity in neurons and glial cells of sections (Figure $3 \mathbf{A}$ ) at $3 \mathrm{~h} \mathrm{(17-}$ fold), $6 \mathrm{~h}$ (15-fold), and $24 \mathrm{~h}$ (10-fold) post-TX near the site of injury (6.5th gill). At locations further from the TX (4th and 1.5 th gill), similar responses were observed at $3 \mathrm{~h}$ (8-fold and 10 fold) and $6 \mathrm{~h}$ (14-fold and 13-fold), respectively. Fluorescence intensity dropped to near control levels by $24 \mathrm{~h}$ post-TX at the 4th (4-fold) and 1.5th-gill (2-fold) (Figure 3C). Thus, Erk phosphorylation is prompt and robust in cells close to the TX. We did not attempt to identify the local cells responding to 
A

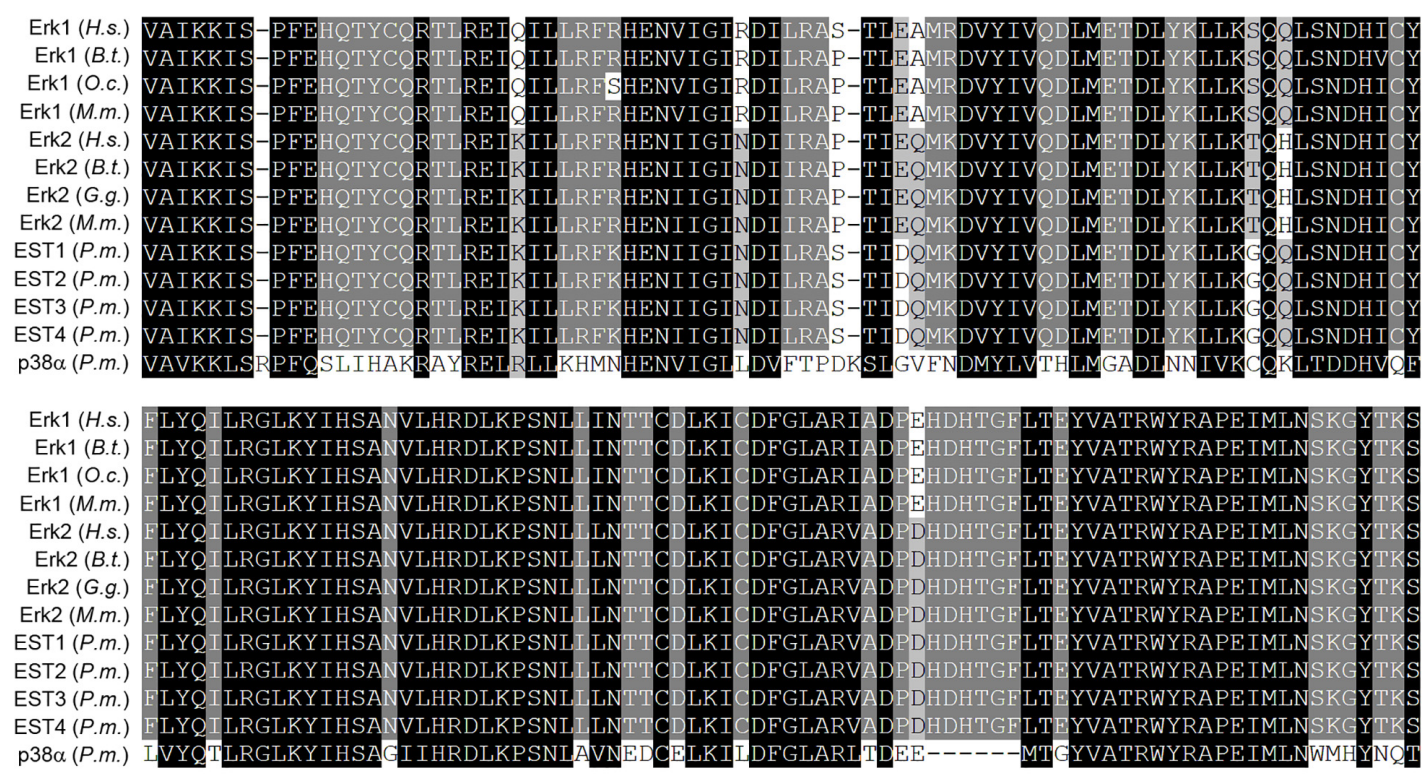

B

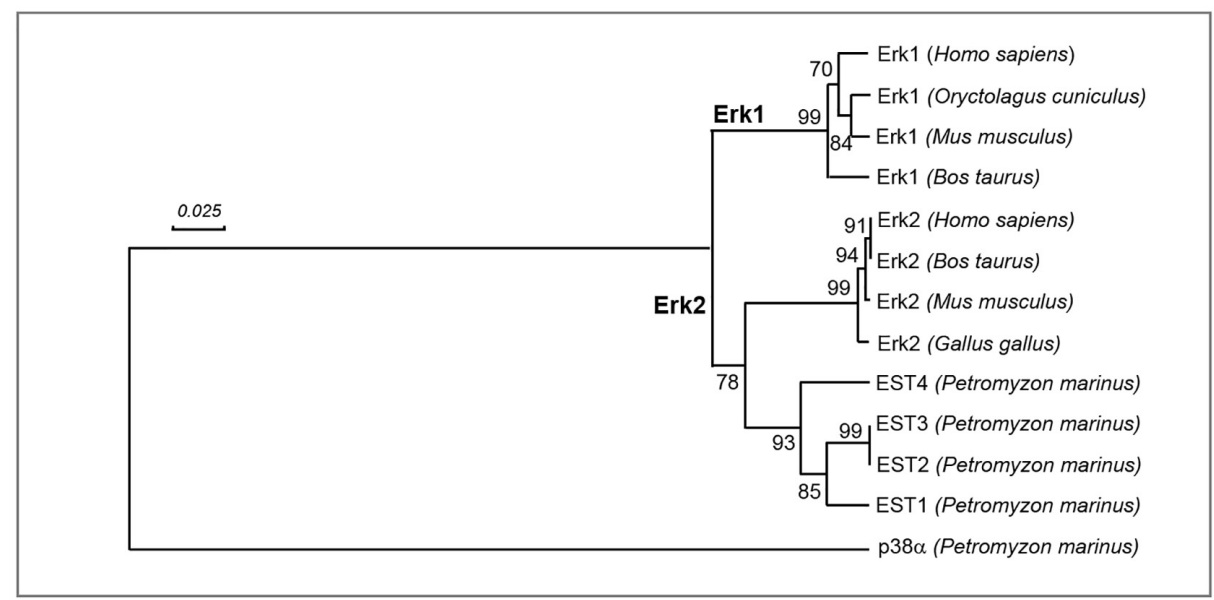

FIGURE 1 | Lamprey lacks Erk1 isoforms. (A) alignment of lamprey and mammalian Erk protein sequences. Thirteen DNA sequences (1 lamprey cDNA, 4 lamprey ESTs, and 8 mammalian CDNAs) were converted to protein sequences and aligned with ClustalX software. The generated MSF file was edited with GeneDoc. Conserved amino acid residues are shaded black. Conservative substitutions are in gray. The two most-conserved blocks (158 amino acids) are presented. (B) positions of lamprey Erks in a phylogenetic tree constructed with human, cattle, rabbit, chicken, and mouse Erks using the "UPGMA" algorithm. Four lamprey protein sequences (EST1-EST4), converted from corresponding erk EST sequences (CDNA), were aligned with 8 mammalian Erks using MEGA-X software (MUSCLE). Four lamprey Erks corresponding to EST sequences CO544767, CO548040, CO545630 and CO547047 were within the Erk2 clade. No lamprey genes were grouped under the Erk1 subtree. Numbers to the left of the branch points indicate the percent of 10,000 bootstrap replicates that support that branch. Lengths in the tree reflect distances between taxa (mean substitutions per residue). Lamprey p38 $\alpha$ was chosen to provide an outgroup for rooting the Erk tree. Scale: 0.025 amino acid substitutions per site.

the TX precisely, but by their sizes and locations, it was clear that the cells showing increased p-Erk labeling included both neurons and glia.

\section{Increased p-Erk Levels Result From the Phosphorylation of Pre-existing Erk}

Next we used chromogenic IHC to determine whether the increase in p-Erk post-TX was due to an increase in Erk expression, or to phosphorylation of pre-existing Erk. Animals were divided into 4 groups as above. The spinal cords were transected at the 7 th gill. Transverse sections were made at the 6.5th gill and chromogenic IHC was performed with primary antibodies against p-Erk and total Erk (t-Erk). In control spinal cords, p-Erk levels were very low (Figures 2B, 4A). Spinal cord TX significantly increased p-Erk levels - at $3 \mathrm{~h}$ by 5.5 -fold; $6 \mathrm{~h}$ by 4.4 -fold; and $24 \mathrm{~h}$ by 1.8 -fold (Figure 4B). This also was true when analysis was limited to the ventral columns, where 


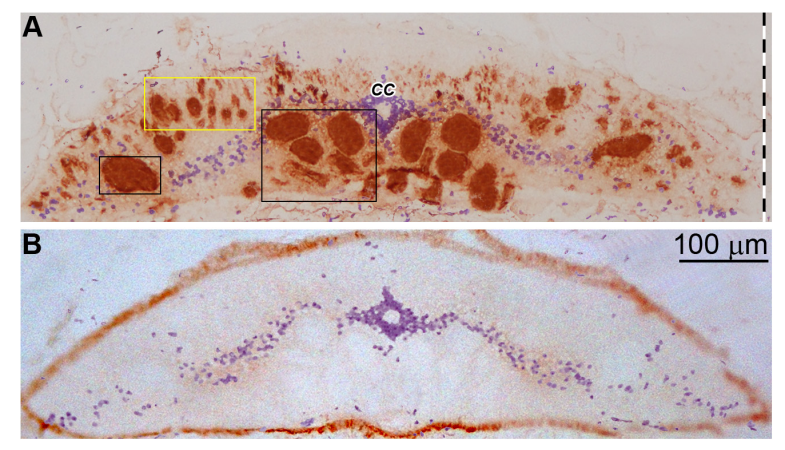

FIGURE 2 | Immunohistochemistry of lamprey spinal cord with LCM16 and p-Erk. (A) One spinal cord (body length $=10.5 \mathrm{~cm}$ ) was sectioned transversely at the 7th gill with a cryostat and stained for neurofilaments with mAb LCM16 (1:100). The slide was stained by SignalStain DAB Chromogen (brown, Cell Signaling Technology) and counter-stained with hematoxylin (blue). Note: LCM16 labels all giant axons and most medium and small caliber axons, but not those in the dorsal columns; hematoxylin labels mostly the nuclei in the gray matter and the ependymal cells surrounding the central canal (CC). Left-sided giant axons that project to the spinal cord are framed by 2 black rectangles. Small and medium-sized axons are framed by the yellow rectangle. (B) Slides from the same animal were probed by anti-p-Erk (1:100, Cell Signaling Technology) and counter-stained with hematoxylin. Note: Little or no $\mathrm{p}$-Erk staining was seen in the giant axons of untransected spinal cord.

the giant Müller axons course (Figure 4B). IHC for t-Erk on the same sections indicated that increases in $\mathrm{t}$-Erk were much less dramatic, although statistically significant at $6 \mathrm{~h}$ (1.78-fold) and $24 \mathrm{~h}$ (2-fold). Quantification in the area containing the giant axons showed no significant increases in t-Erk (Figure 4C). This suggests that the increases in p-Erk levels in whole spinal cord or in the giant axons are mostly due to phosphorylation of existing Erk.

\section{Spinal Cord TX Increases the Number of Intra-axonal p-Erk-Containing Granules}

We examined changes in intra-axonal p-Erk-containing granules at 3 spinal cord locations ( $\mathrm{S} 1, \mathrm{~S} 2$, and S3 in Figure 3B) in previously transected spinal cords (Figure 5). LCM16 was used to identify axon profiles, and DAPI nuclear staining was used to identify cell bodies. Twelve animals were divided into 4 groups (untransected Ctrl, and 3, 6, and $24 \mathrm{~h}$ post-TX). Representative immunofluorescence images (Figure 5A) showed p-Erk labeling at $3 \mathrm{~h}$ in sections at S2. In addition to intra-axonal granules (red arrowheads), there were patches of more diffuse intra-axonal staining (yellow arrowheads). Immunolabeling for intra-axonal p-Erk was mostly diffuse at $3 \mathrm{~h}$ and replaced by granules at $6 \mathrm{~h}$ post-TX (Figure 6). For each frozen section, p-Erk-positive granules were counted at high magnification in six cross-sectional regions of axons (Figures 5Aa-f). The small-medium sized axons of the dorsolateral areas had far fewer p-Erk-positive granules than did the large Müller axons of the ventral columns and the Mauthner axons of the lateral columns. The small axons of the dorsal columns were not counted because they were mainly rostral-projecting and thus any movement of granules detected in them could not be assumed to be centripetally oriented. In addition, those axons do not stain prominently with LCM16. Nevertheless, the dorsal columns contained almost no p-Erkpositive granules.

Granules were counted in 4 serial sections taken from each of the three sampled spinal cord levels (S1, S2, and S3). Some intraaxonal granules were found inside areas of diffuse pErk staining and also were included in the count. Intra-axonal granules were rare in untransected control animals $(2.2 \pm 0.6,1.9 \pm 0.7$, and $2.7 \pm 0.9$ per entire section at levels S1, S2, and S3, respectively). After TX, granules in large Müller and Mauthner axons increased earliest at S1, reached an approximately 32.7-fold peak increase by $6 \mathrm{~h}$ at S1 and 31.5-fold increase at S2, falling from those levels by $24 \mathrm{~h}$. However, at S3, granule numbers were still rising at $24 \mathrm{~h}$. This was true for both large and small-medium sized axons (Figure 5B). These findings suggest that Erk is activated (phosphorylated) near the lesion, and is translocated rostralward in granules.

\section{Fluorescence IHC Detection of p-Erk in Horizontal Sections of Transected Lamprey Spinal Cord}

To further support the hypothesis that Erk is activated initially at the TX site and then retrogradely transported, we performed IHC on horizontal sections and determined the location of maximal p-Erk staining at $0,3,6$ and $24 \mathrm{~h}$ post TX. The lamprey spinal cord is approximately $225 \mu \mathrm{m}$ thick, yielding about 15 sections per length of spinal cord when sectioned at $15 \mu \mathrm{m}$ (Dash line in Figure 2A). Small or medium caliber axons are observed in the dorsal-most 4-7 sections. The giant RS axons are encountered in the 8th-11th sections (Figure 2A). The distribution of p-Erk-containing granules along axons was studied by immunofluorescence. Horizontal sections of spinal cord encompassing the 4.5 th to 7 th gill (approximately $4.5 \mathrm{~mm}$ ), were immunolabeled for p-Erk at $6 \mathrm{~h}$ post-TX. A representative section is seen at low magnification in Figure 7A. Immunofluorescence was diffuse in longitudinal profiles close to the TX site, consistent with the results in transverse sections. At higher magnification individual granules could be discerned (Figures 7A,a-d). Even within this length of spinal cord corresponding to S1, granule density was highest near the TX site. To confirm that these p-Erk-positive granules were inside axons we double-labeled the sections for neurofilament with LCM16 (Figures 7B,a-f). Statistical analysis showed that at $6 \mathrm{~h}$ post-TX, the number of p-Erk granules were significantly higher in giant, medium, and small-caliber axons than in corresponding sized axons of untransected spinal cords, and the difference was more extreme the larger the axons (Figure 7C). To eliminate a contribution to the findings from autofluorescence (Chen et al., 2015), we also performed chromogenic IHC in normal and transected spinal cord (data not shown). Serial horizontal sections of spinal cords 3 or $6 \mathrm{~h}$ post-TX, or from untransected controls, were incubated with p-Erk antibody, and visualized by biotinylated horseradish peroxidase (HRP). There was little or no p-Erk staining in sections of control spinal cord. Spinal cord TX elicited strong p-Erk staining at the TX site by 3 and $6 \mathrm{~h}$. 


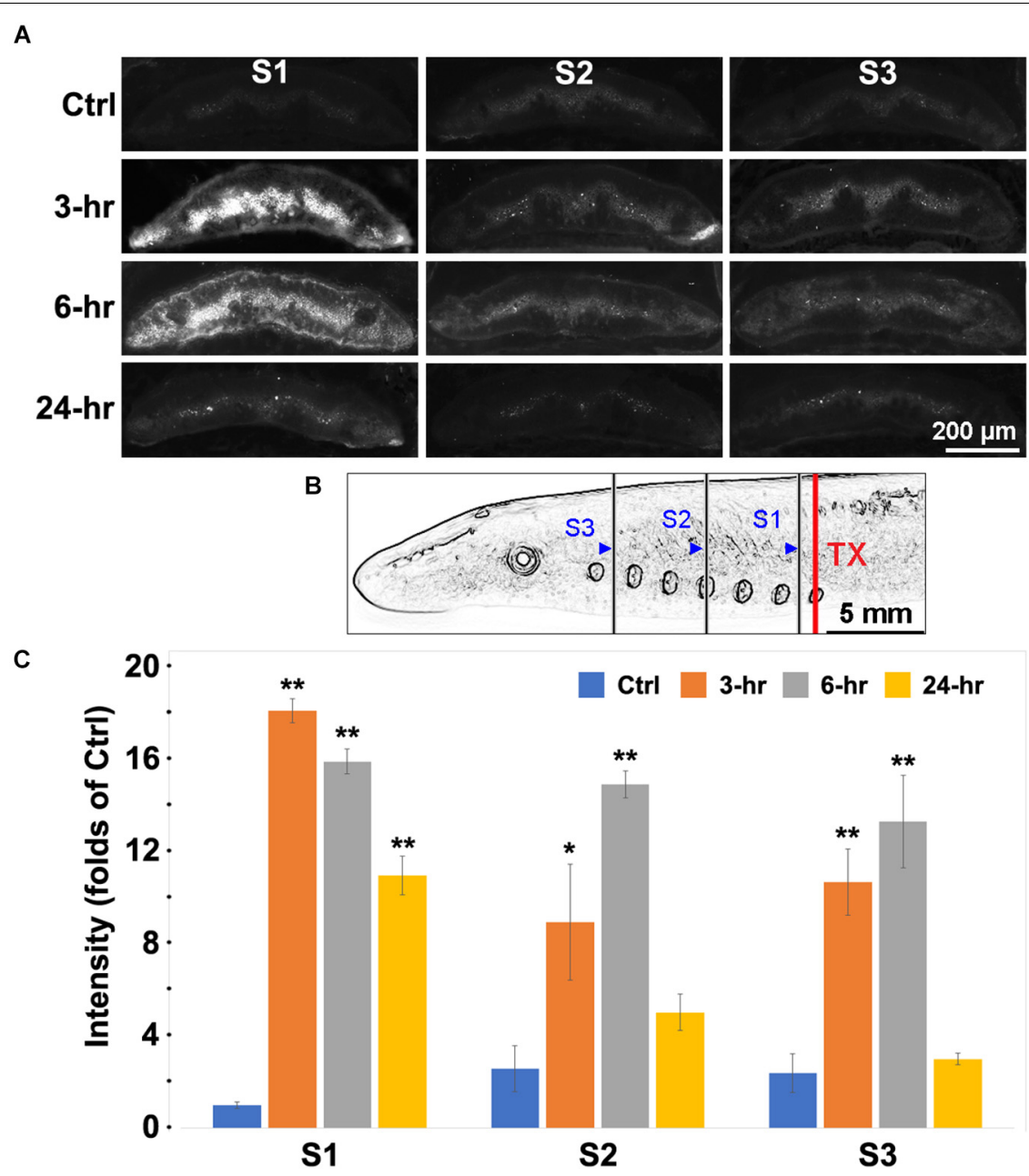

FIGURE 3 | Labeling for p-Erk was increased after spinal cord TX. (A) Fluorescent images of transverse sections of spinal cord at locations S1, S2, and S3 were obtained in 4 time groups: No TX (Ctrl), 3, 6, and $\mathbf{2 4} \mathbf{~ h}$ post-TX. Slides were labeled with a primary antibody against p-Erk, and fluorescently labeled secondary antibody (AF-594). The strongest p-Erk staining was found at 3 and $6 \mathrm{~h}$ in gray matter near the TX (C1). (B) schematic illustration of the S1, S2, and S3 body locations at which the spinal cord was imaged after TX at the 7th gill. Blue triangles: caudal boundaries of the body lengths for transverse sectioning. S1 = the length between the 4th and 6.5th gills; S2 = 1.5th-4th gill; S3 = Head-1.5th gill. (C) quantification of p-Erk response to TX. Spinal cord TX significantly increased the p-Erk labeling at 3 and $6 \mathrm{~h}$ at all sites. (Mean $\pm \mathrm{SEM}, n=4 ;{ }^{*},{ }^{* *} p<0.05 / 0.01$ over Ctrl, respectively, one-way ANOVA followed by Dunnett's test).

\section{Spinal Cord TX Increases Vimentin mRNA and Protein Levels Rostral to the Lesion}

In order to determine whether spinal cord TX increases the levels of vimentin mRNA in RS axons close to the injury, we performed ISH. Four control lampreys and four lampreys $6 \mathrm{~h}$ post-TX at the 7 th gill, were killed and the body lengths between the 4th and 6th gill were cryo-sectioned. ISH was performed with a vimentin antisense probe. Other slides were used for chromogenic IHC with an anti-vimentin antibody. Both vimentin mRNA and protein were elevated in the transected spinal cords compared to controls. In the untransected spinal cord, vimentin mRNA and protein were present mostly in cell bodies of the gray matter and in the glial scaffold. No structures were labeled by the control sense probe. Intra-axonal levels were low (Figure 8A). Spinal cord TX increased extra-axonal vimentin
mRNA and both intra-axonal and extra-axonal vimentin protein (Figure 8A). These findings were confirmed with Western blots. Thirty animals were separated into five groups (control, and transected at the 7 th gill, with recovery for $1,3,6$ or $24 \mathrm{~h}$ ). Spinal cords between the TX site and the 1st gill were collected and cut into 2 pieces, P1 (caudal) and P2 (rostral) as shown in Figure 8B. Tissues were homogenized and separated in 10\% SDS gel. A representative Western blot is shown in Figure 8C. Vimentin expression was significantly increased at $6 \mathrm{~h}$ (P1) and $24 \mathrm{~h}$ (P2) post-TX, respectively (Figure 8D).

\section{Vimentin Does Not Colocalize With p-Erk}

Axons of different calibers were examined by fluorescence microscopy in horizontal sections after double immunolabeling for $\mathrm{p}$-Erk and vimentin (Figure 9). Linear arrays of p-Erkpositive granules (red) were gathered in regions of axon tracts. 


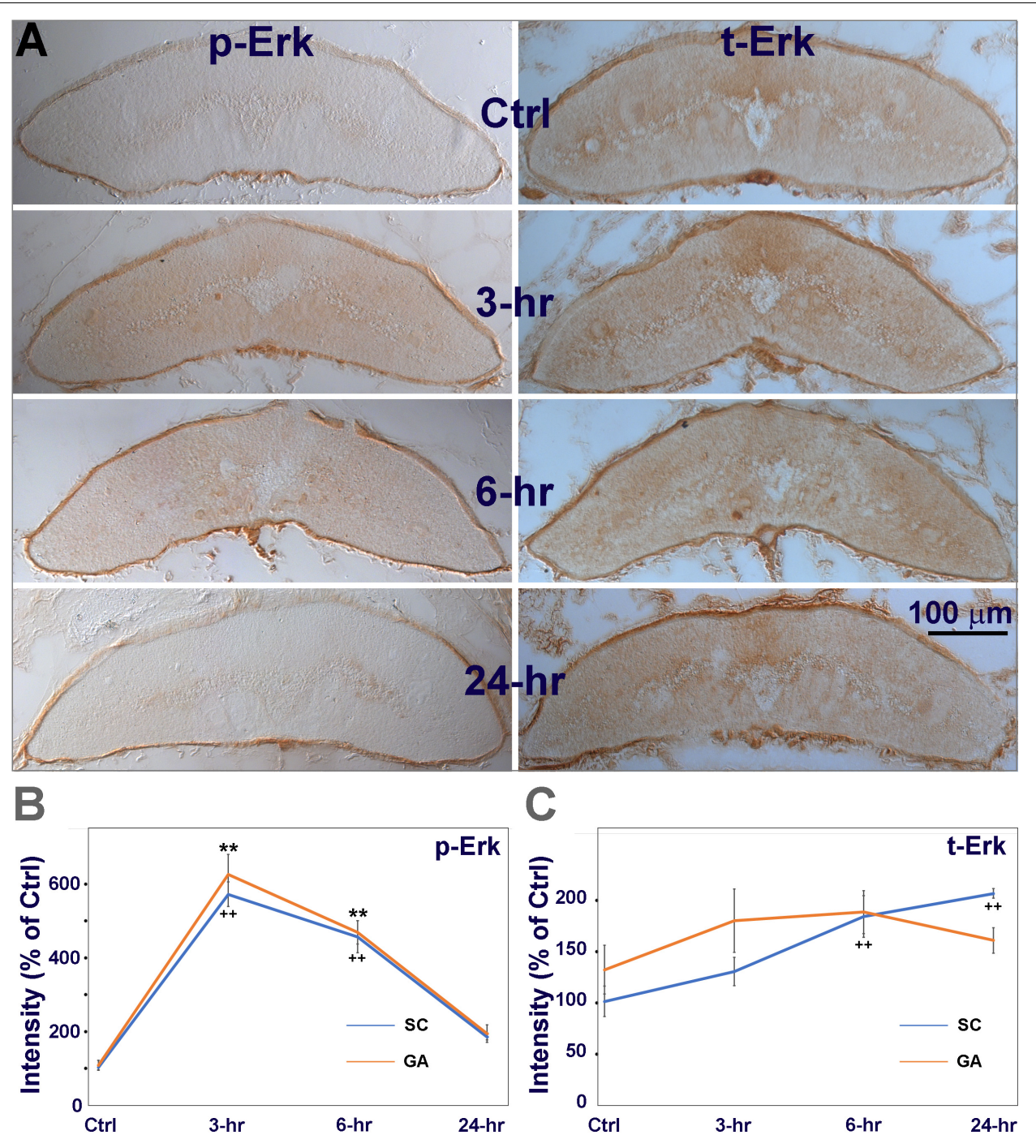

FIGURE 4 | The increase in p-Erk is due mostly to phosphorylation of pre-existing Erk. (A) chromogenic IHC for phosphorylated Erk (p-Erk), and total Erk (t-Erk). Animals had a spinal cord TX at the level of the 7th gill. Transverse sections near the TX site ( 6.5th gill) were collected from 4 groups of animals. Animals were sacrificed immediately (Ctrl), or at $\mathbf{3}, \mathbf{6}$, or $\mathbf{2 4} \mathrm{h}$ post-TX. Left, spinal cord immunolabeled with a p-Erk antibody, Right, labeled with a t-Erk antibody.

(B) Quantification of immunolabeled p-Erk in whole spinal cord (SC) and in giant axons (GA, as defined in Figure 1A). In both SC and GA, Erk was significantly activated (phosphorylated) at 3 and $6 \mathrm{~h}$ post-TX (5-6 fold over Ctrl), and returned to low levels by 24 hours. (C) total Erk was increased both in SC (1.5 2 fold) and GA (1.5-fold) (Mean \pm SEM, $n=6$ animals; ${ }^{* *},{ }^{++} p<0.01$ over Ctrl in GASSC, respectively, one-way ANOVA followed by Tukey test). Thus, the increase in t-Erk was too small to account for the large increase in $p$-Erk.

The absence of DAPI DNA staining in all triple-superimposed images (Figures 9A3-D3) indicates that the linear arrays are not in the gray matter. By contrast, vimentin-positive particles (green) were located outside the axons (Figure 9D), and did not colocalize with p-Erk.

\section{Dynein Colocalizes With p-Erk}

Double-label IHC was used to determine whether the retrograde movement of p-Erk involves the molecular motor dynein. The specificity of the anti-dynein primary antibody (MAB1618, Millipore) for lamprey dynein was checked by Western blotting of protein isolated from normal lamprey spinal cord (Figure 10A). A double band was detected at approximately
$74 \mathrm{kDa}$, similar to dynein in mammals (Pfister et al., 1996). IHC in transverse sections showed that dynein was present diffusely throughout the spinal cord (Figure 10B), including cell bodies in gray matter and axons. Horizontal sections from four spinal cords $6 \mathrm{~h}$ post-TX at the 7th gill were reacted with antibodies to dynein and p-Erk. Figure 10 illustrates the result in several small-caliber axons (Figures 10D,E) and one giant axon (Figure 10C). Approximately $88 \%$ of granules were doublelabeled, indicating colocalization of p-Erk and dynein. Dynein is a universal retrograde molecular motor, so it is widely distributed in axons, and is associated with a large variety of cargos of different sizes, whereas only a small fraction of their cargo are the p-Erk-containing granules. This may make it difficult to intuit 


\section{A}
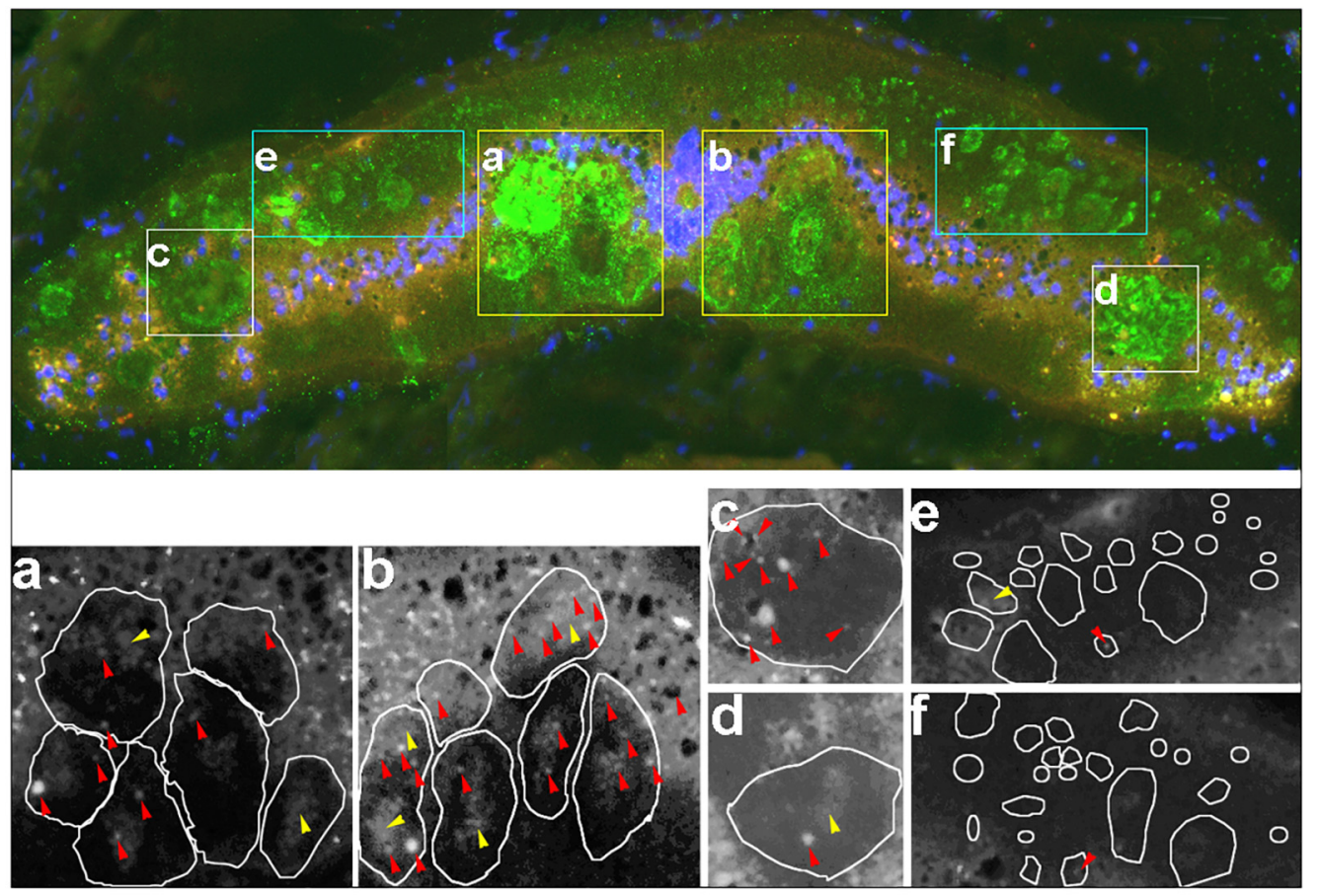

B
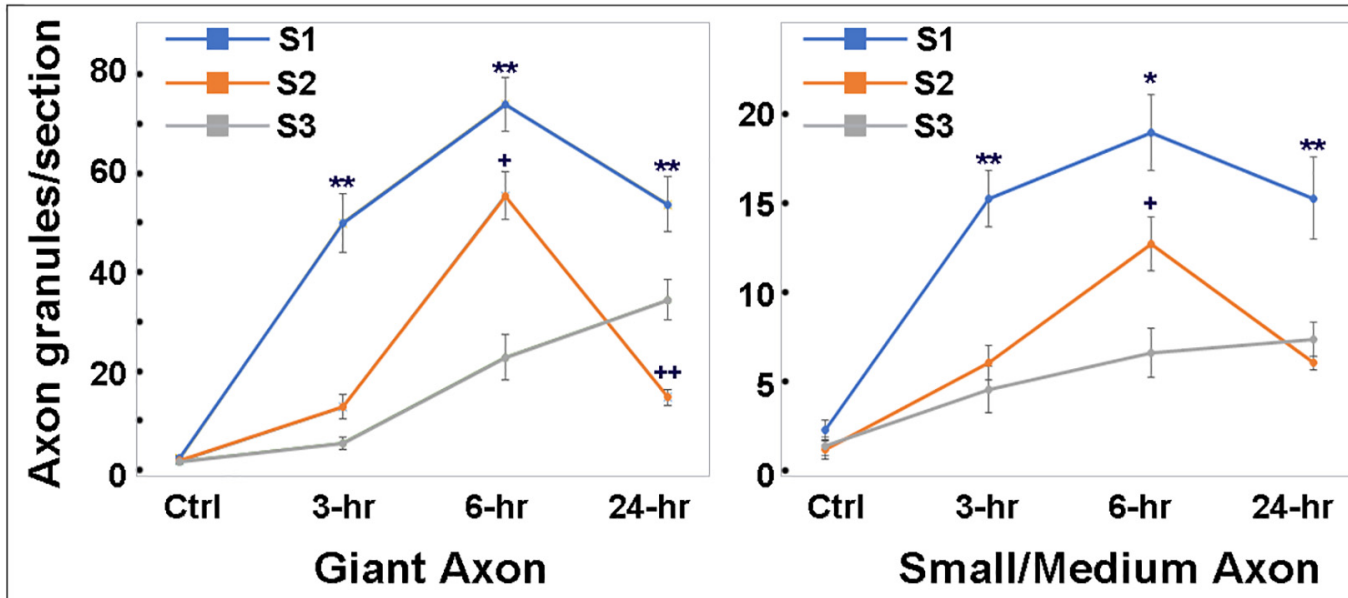

FIGURE 5 | Time course for phospho-Erk distribution in axons of transected spinal cord. (A) Top panel, a representative transverse section at S2 level of a spinal cord at $3 \mathrm{~h}$ post-TX, stained with a p-Erk pAb (red), LCM16 mAb (green) and DAPI (blue). Axons stained with LCM16 were clustered into 6 regions (a-f). Bottom panel, magnified black and white images from the red channel for the 6 regions in the top micrograph, showing p-Erk granules. Irregular circles are axon profiles identified by LCM16 staining. $(\mathbf{a}, \mathbf{b})$, granules inside giant axons in the ventral columns. Red arrowheads point to isolated granules; yellow arrowheads point to diffuse intra-axonal staining. (c,d), granules inside the Mauthner axons in the lateral columns. (e,f), granules inside small-medium axons in dorsolateral columns are less numerous than those in the largest axons. The small axons of the dorsal columns are not sampled because these axons are primarily rostral-projecting and also stain poorly with LCM16, but they too have almost no p-Erk-containing granules. (B) at 3, 6, and $24 \mathrm{~h}$ post-TX, granule numbers at 3 locations (S1, S2, and S3) are significantly greater than in controls $(p<0.01$, one-way ANOVA). Granule numbers at S1 of transected spinal cords are significantly greater than those at S2 and S3 (Mean \pm SEM, $n=10 ;{ }^{*},{ }^{* *} p<0.05 / 0.01$ over S2, respectively, ${ }^{+,}{ }^{++} p<0.05 / 0.01$ over S3, respectively, one-way ANOVA followed by Tukey test).

the colocalization of dynein and p-Erk-containing granules. To ameliorate this problem, in Figure 10, we placed boxes around the p-Erk-positive granules, white boxes for those also associated with dynein immunolabeling, and cyan boxes for those not associated with dynein immunolabeling. We then verified the colocalization of dynein with p-Erk by performing a Pearson's correlation analysis. Twenty rectangular areas $(160 \times 50 \mu \mathrm{m})$ were randomly selected from 10 captured images to count the 

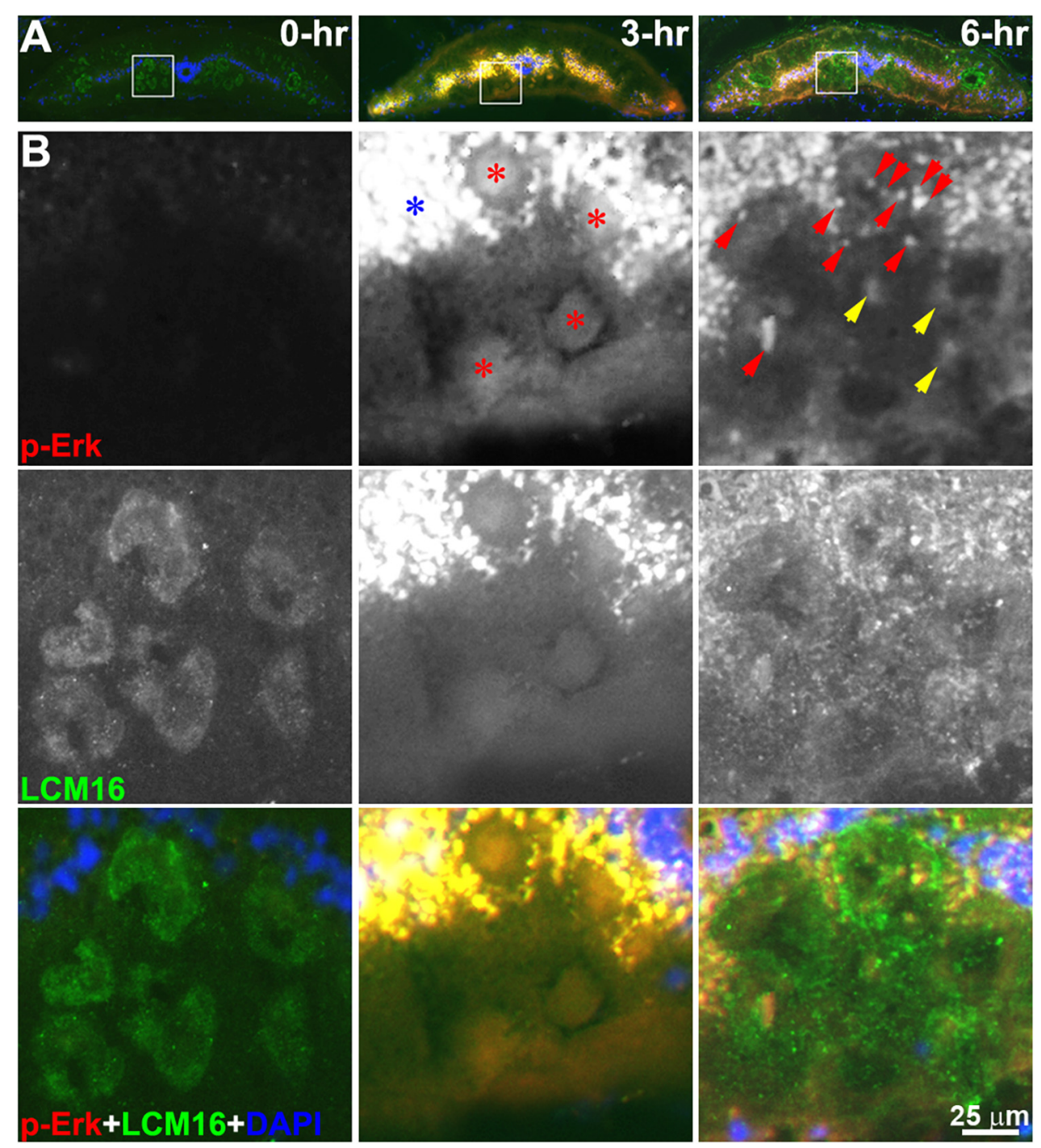

FIGURE 6 | p-Erk staining becomes localized in granules by $6 \mathrm{~h}$ post-TX. (A) superimposed triple staining of cross sections at the level of the 6.5 th gill in control (0-h) and transected (7th gill) spinal cords (3-h and 6-h). (B) enlarged squares in panel (A). Two monochromic images in each column represent p-Erk and LCM16 labeling, respectively. The color images at the bottom is superimposed of $\mathrm{p}$-Erk, LCM16 and DAPI staining. Diffuse $\mathrm{p}$-Erk staining was found inside axons at $3 \mathrm{~h}$ post-TX (red stars), and in cells of the gray matter (blue star). Both granules (red arrowheads) and diffuse stain (yellow arrowheads) were found in axons of transected spinal cord at 6-h post-TX. Red, p-Erk; Green, LCM16; Blue, DAPI.

p-Erk-positive granules with and without dynein staining. The data were analyzed by linear regression. The strong positive correlation between $\mathrm{p}$-Erk and dynein staining in granules is shown in Figure 10F $(y=0.902 x-0.431, r=0.991, n=20)$.

\section{Axotomy Increases Phosphorylation of Erk in the Spinal Cord and of C-Jun in the Brainstem}

To further elucidate the role of Erk in retrograde signaling of injury, after spinal cord TX, we evaluated the changes in p-Erk levels in the spinal cord, and c-Jun, a potential target of p-Erk, in the brainstem, where the spinal-projecting neurons are located. Twenty-four lampreys in six groups (control, and
$0.5,1.5,3,6$, and $24 \mathrm{~h}$ post-TX) were used in these assays. Western blots showed that phosphorylation of both proteins appears at $0.5 \mathrm{~h}$ post-TX (Figure 11). Erk activation was dramatically increased even at $0.5 \mathrm{~h}$, reaching a peak at $6 \mathrm{~h}$ but remaining significantly elevated at $24 \mathrm{~h}$. Quantitation of t-Erk showed no significant increase post-TX. An increase of $120 \pm 19 \%$ of control, observed at $6 \mathrm{~h}$ post-TX, was not statistically significant (one-way ANOVA). Phosphorylation of c-Jun also rose rapidly, reaching a peak at $1.5 \mathrm{~h}$, but by $24 \mathrm{~h}, \mathrm{p}$-c-Jun had returned to normal levels. Although at $0.5 \mathrm{~h}$, the increase in p-Erk was more dramatic than that of c-Jun, we cannot exclude that they rose in parallel, rather than that the rise of $\mathrm{p}$-Erk in the spinal cord preceded that of c-Jun in the brain. 

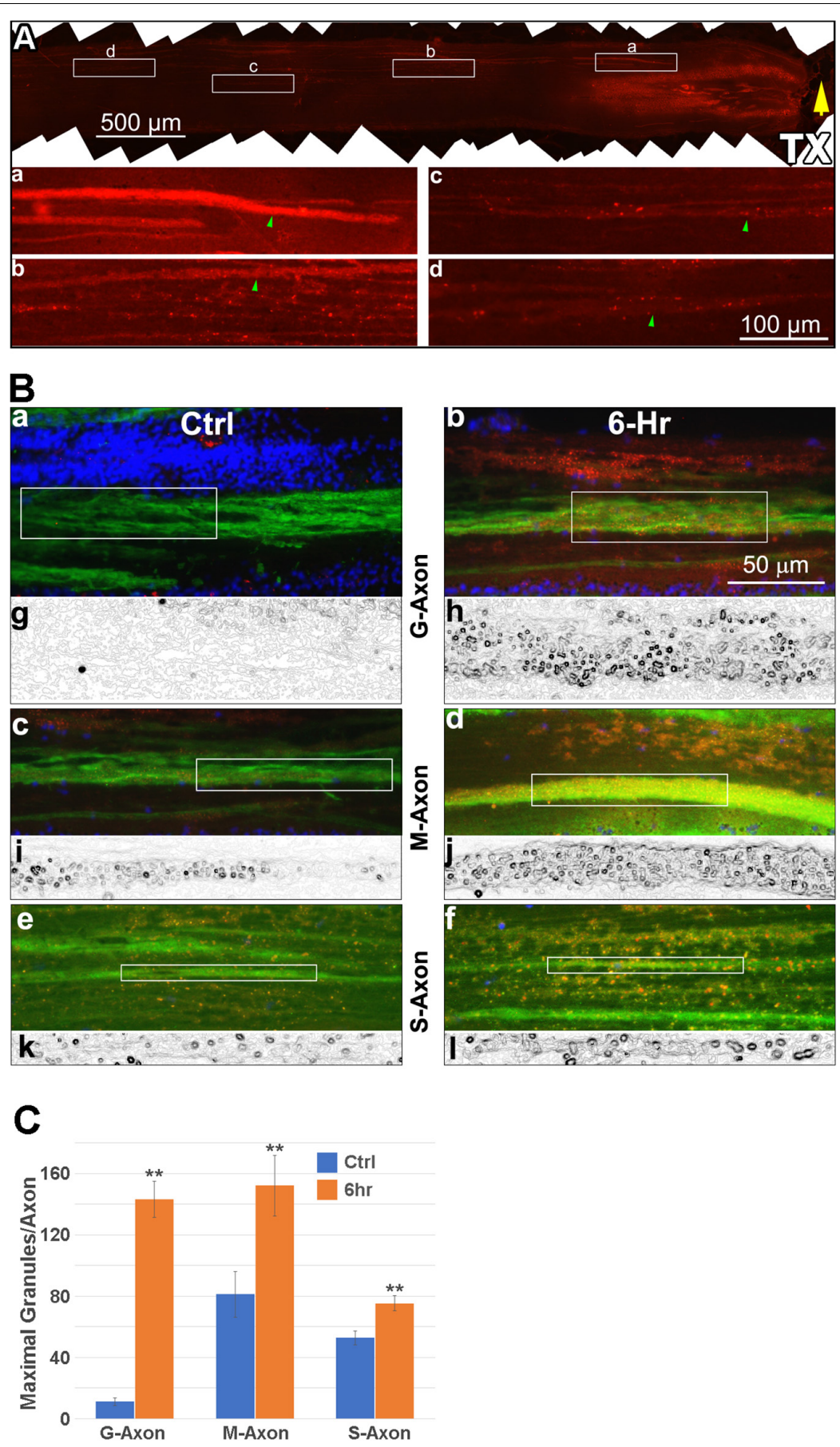

FIGURE $7 \mid \mathrm{p}$-Erk staining is increased in axons after TX. Six spinal cords were transected at the level of the 7 th gill, and $6 \mathrm{~h}$ later, immunolabeled with antibodies for p-Erk and neurofilaments (LCM16), followed by AF594- and AF488-labled secondary antibodies, respectively. Four untransected animals were used as controls. (A) a representative immunofluorescence image of $\mathrm{p}$-Erk labeling in a horizontal section covering the spinal cord between the 4.5th and 7th gill (rostral is left). Rectangles (a-d), shown enlarged below each frame, enclose $500 \mu \mathrm{m}$ lengths of axon that are continuously present at maximum width within the section, and thus contain the maximum number of granules. The images illustrate the progressive reduction in p-Erk staining with distance rostral to the TX. Green arrowheads: 4 axons of similar caliber (10-11 $\mu \mathrm{m}$ width). (B) $\mathrm{IHC}$ for p-Erk in axons located at the -6th gill area, 1-2 $\mathrm{mm}$ from the site of TX at the 7th gill. (a,b), giant axons (G-Axon, caliber > $30 \mu \mathrm{m})$; (c,d), medium-caliber axons (M-Axon, 15-30 $\mu \mathrm{m})$; (e,f), small-caliber axons (S-Axon, $<15 \mu \mathrm{m})$ in spinal cords with (6-h) and without (Ctrl) TX, respectively. Red: p-Erk; Green: LCM16; Blue: DAPI. The boxes enclose $100 \mu \mathrm{m}$ lengths of axon that are continuously present at maximum width within the section, and contain the maximum number of granules. (g-l), binary images of the red channel in panels (a-f), processed with the tool "Find Edges" (Adobe Photoshop CS4), to highlight countable round granules. (C) comparison between the numbers of $\mathrm{p}$-Erk granules per $100 \mu \mathrm{m}$ length of axon in spinal cords with TX vs. without TX. For each size category, the numbers of granules found in axons at $6 \mathrm{~h}$ post-TX are significantly greater than in the untransected control group (Mean \pm SEM, $n=8-15$ sections, ${ }^{* *} p<0.01$, Student's $t$-test). 
A
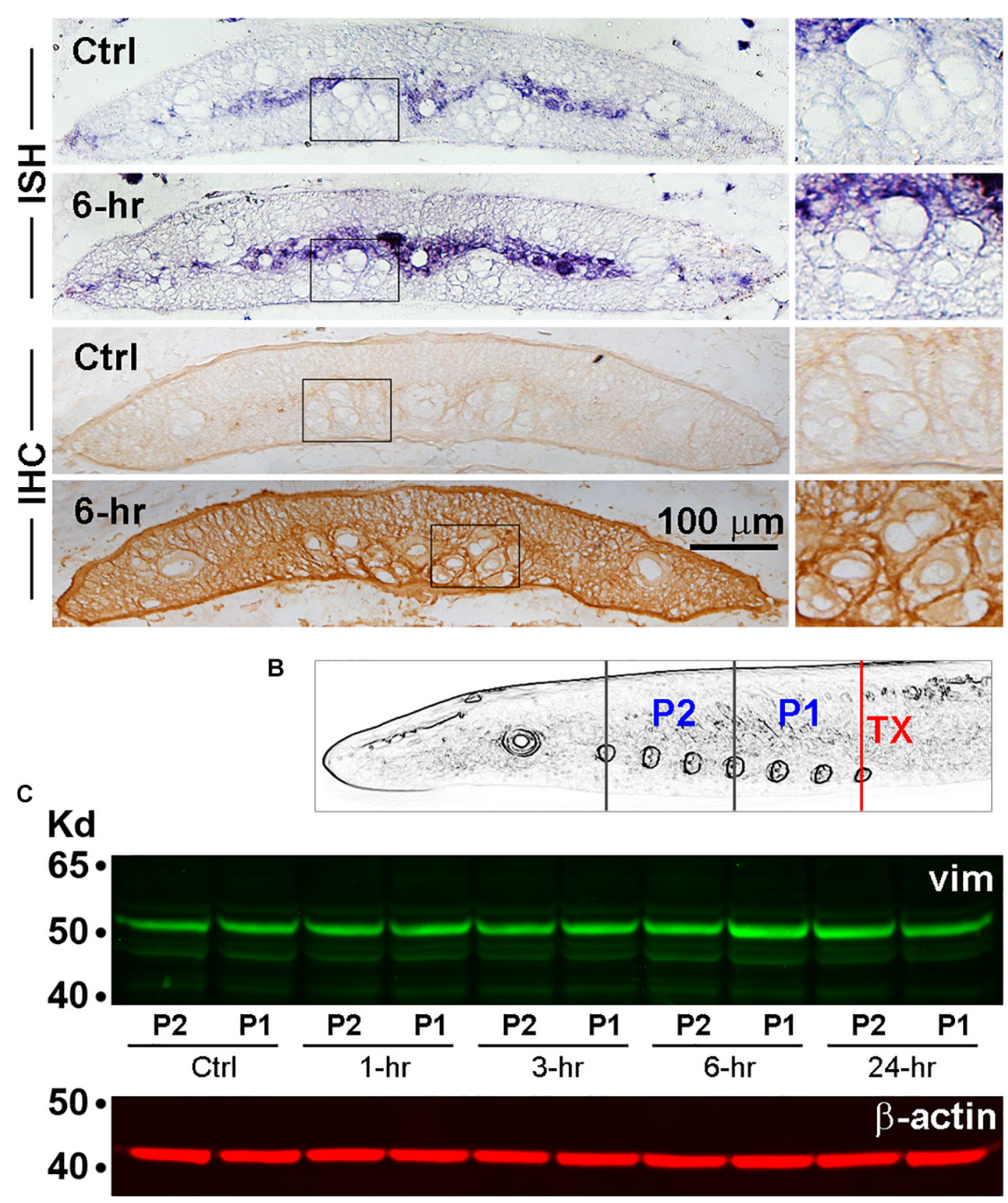

D

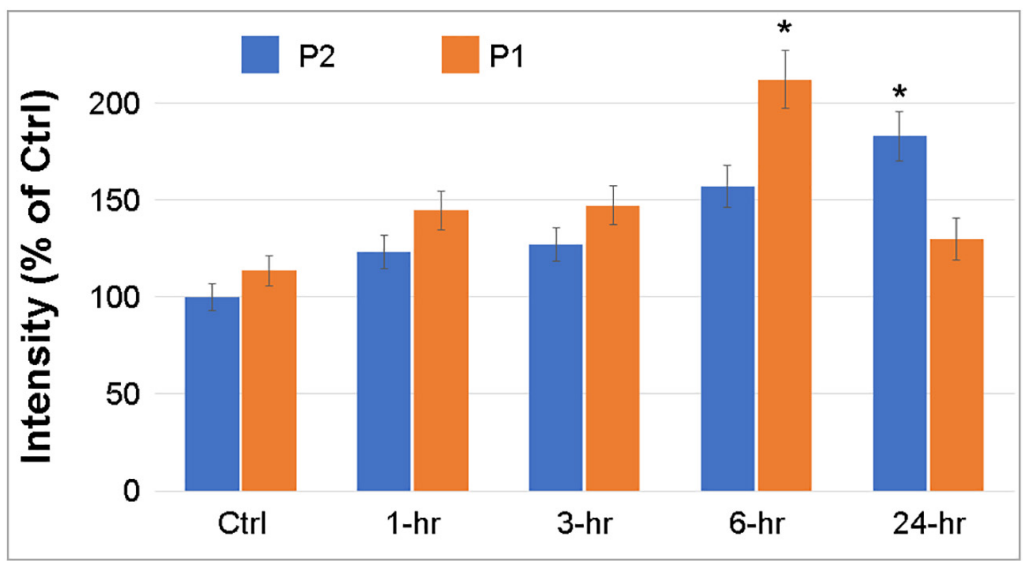

FIGURE 8| Vimentin expression is increased by spinal cord TX. (A) Transverse sections of spinal cord at the level of the 6th gill collected from either control animals or animals $6 \mathrm{~h}$ post-TX at the level of the 7th gill. ISH and IHC for vimentin were performed on sections close to the TX site. Each process was repeated twice in each of 4 animals/group. Right panels are magnified views of the corresponding boxed areas. (B) Schematic illustration of the locations of spinal cord lengths sampled for vimentin Western blotting. Six spinal cords/group at 5 time points (Ctrl, and $\mathbf{1}, \mathbf{3}, \mathbf{6}$, and $\mathbf{2} \mathbf{4} \mathbf{~ h}$ post-TX at the 7 th gill) were homogenized by sonication. Each spinal cord was divided into 2 pieces: $\mathrm{P} 1=4$ th gill to 7 th gill, $\mathrm{P} 2=1$ st gill to 4 th gill. (C) Western blotting was performed with mAbs against vimentin $(1: 1000$, V6630, Sigma) and secondary antibody IRDye 800CW (926-32210; LI-COR). Loading controls ( $\beta$-actin) are shown underneath. (D) Quantification of signals from (C) with ImageJ, after correction for background (Mean \pm SEM, $n=3$ animals/group. ${ }^{*} p<0.05$ vs. control by ANOVA followed by Dunnett's test). 

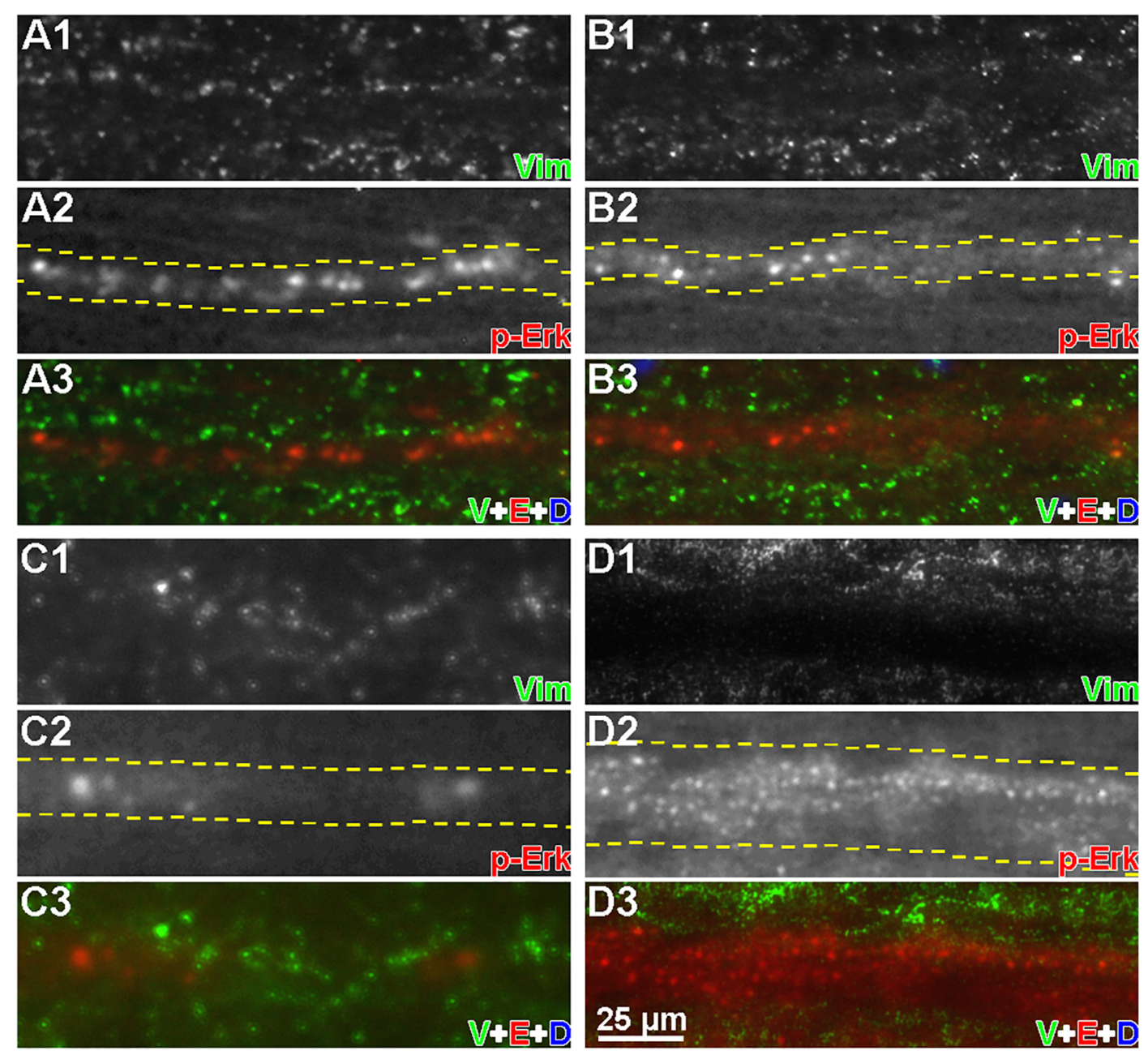

FIGURE 9 | Vimentin and p-Erk are not colocalized in axons. Horizontal cryostat sections of spinal cords, each focused on a single axon, at $6 \mathrm{~h}$ post-TX were immunofluorescence labeled with anti-p-Erk and anti-vimentin antibodies. (A1-D1) show vimentin staining; (A2-D2) show p-Erk staining (white). Dashed lines indicate the axon boundaries; (A3-D3) show vimentin (green), p-Erk (red), and DAPI (blue) staining superimposed. (A,B) small caliber axons; (C) a medium caliber axon; (D) a large caliber axon. It was not possible to keep the entire length of axon in the plane of focus. Nevertheless, it can be seen that the vimentin stain was largely outside the axons, and not colocalized with $\mathrm{p}$-Erk ( $n=3$ animals/group).

\section{DISCUSSION}

Several mechanisms have been proposed to explain how axons signal injury to their perikarya. Ions and biological macromolecules have been identified as retrograde injury signals, acting over seconds to minutes to days or even weeks (Ambron and Walters, 1996). In dorsal root ganglion (DRG) cells, complexes of Erk1/2 with other proteins have been postulated as retrograde injury signals (Hanz and Fainzilber, 2006). Much less is known about retrograde injury signals in the CNS, where assessment in mammals is complicated by several factors described in section "Introduction". Here we report that at the site of spinal cord TX in the lamprey, activated Erk accumulates in RS axons near the site of injury, is translocated retrogradely to the perikarya in the brainstem, where c-Jun is activated. The activation of Erk is detected by $0.5 \mathrm{~h}$ post-TX, and lasts more than $24 \mathrm{~h}$ in the injured spinal cord. Because increased c-Jun activity also was detected by $0.5 \mathrm{~h}$, and peaked by $1 \mathrm{~h}$, whereas p-Erk levels peaked at $6 \mathrm{~h}$, it was not possible to conclude that the Erk activation preceded that of c-Jun, even though at $0.5 \mathrm{~h}$ the increase in p-Erk was much greater than that of c-Jun. It is possible that the c-Jun activity in the brain was triggered at least in part by other factors, such as injury discharges that could lead to very rapid calcium-mediated c-Jun responses (Murphy et al., 1991; Cruzalegui et al., 1999).

\section{Lampreys Lack Erk1}

In this study, antibodies to p-Erk (phosphorylated) and t-Erk (pan-specific) were used. In mammals, these antibodies do not distinguish Erk1 from Erk2 because they share 83\% amino acid identity (Cargnello and Roux, 2011). In the present study, Western blots of CNS homogenates, using both antibodies, identified only a single Erk band. This was supported by DNA sequence analysis. A phylogenetic tree was constructed with 8 

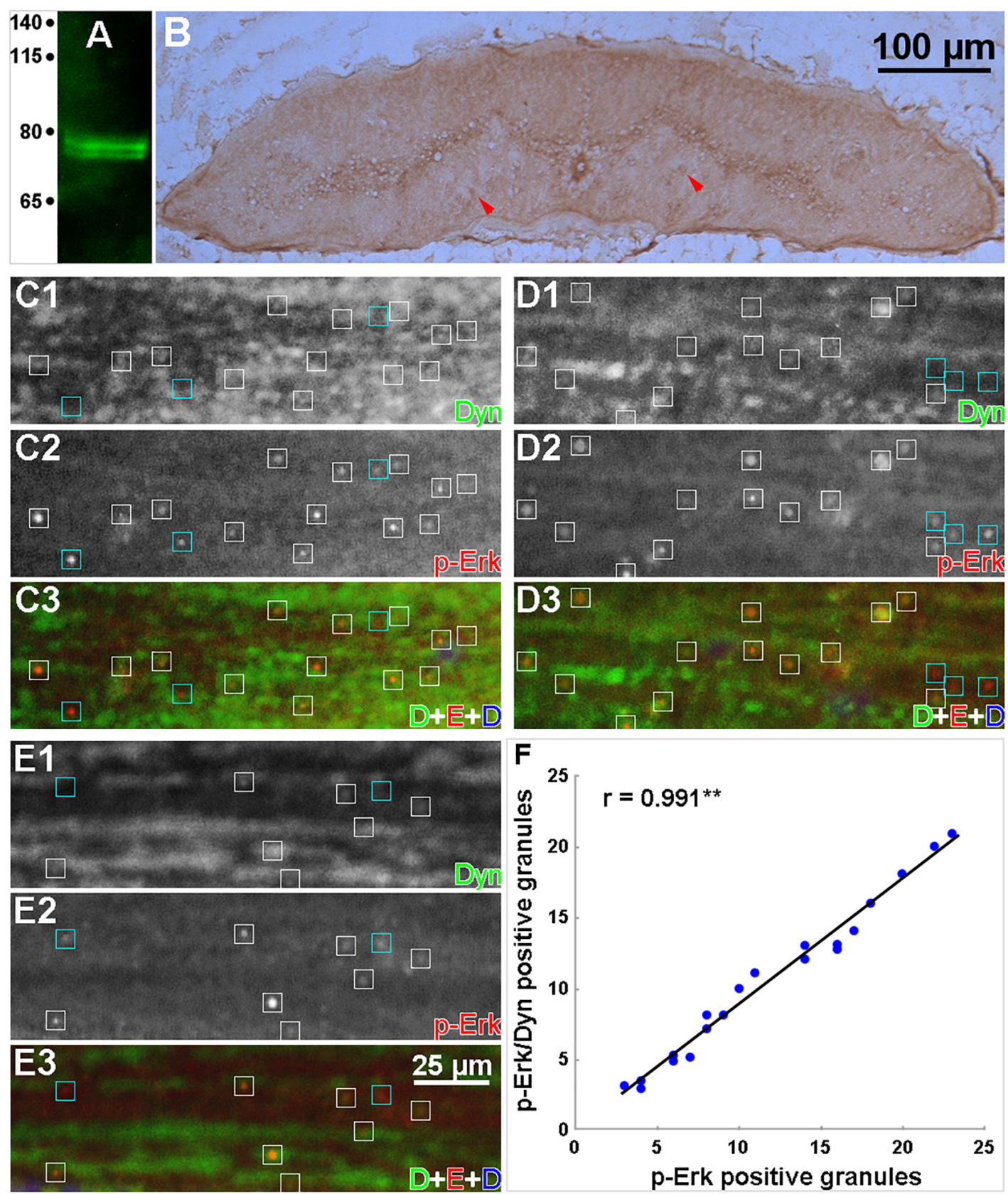

FIGURE 10 | Colocalization of dynein and p-Erk in intra-axonal granules. (A) Western blot of proteins prepared from lamprey spinal cord, probed with an anti-dynein mAb. Two closely migrating bands were labeled at approximately $74 \mathrm{kDa}$. (B) $\mathrm{HC}$ in a transverse section of normal lamprey spinal cord labeled with the anti-dynein $\mathrm{mAb}$, showing diffuse dynein expression in both cell bodies and axons (red arrowheads). (C-E) data were collected from 2 experiments on 4 animals. Horizontal cryostat sections of spinal cords at $6 \mathrm{~h}$ post-TX were double-labeled immunofluorescently for p-Erk and dynein, and stained for DNA with DAPI. (C1-E1), dynein staining; (C2-E2), p-Erk staining; (C3-E3), dynein (green), p-Erk (red), and DAPI (blue) superimposed. White boxes enclose double-labeled granules; Cyan boxes enclose single-labeled ( $p$-Erk) granules. Most p-Erk-labeled granules (88\%) also are dynein-labeled. The absence of DAPI staining indicates that the granules shown are in axon tracts, not in areas with cell bodies. (F) fluorescent images captured in panels (C-E) were used for Pearson's correlation analysis. Twenty areas $(160 \times 50 \mu \mathrm{m})$ were randomly selected for counting granules of p-Erk and dynein staining. Data analyzed by linear regression (SigmaStat) revealed a strong positive correlation between $p$-Erk and dynein labeling $\left({ }^{\star \star} p<0.001, n=20\right)$. Because dynein is a universal retrograde molecular motor, it is widely distributed within the axons, and it may be difficult to intuit this colocalization by inspection without the statistical analysis.

mammalian Erk genes, four of them Erk1, and another four of them Erk2. Four lamprey EST sequences were incorporated into the tree. Four ESTs (CO544767, CO548040, CO545630, and
CO547047) (Pancer et al., 2004) belonged to the erk2 clade, and one turned out to be a homolog of MAPKK. No Erk1 isoform was found. Thus, the sea lamprey appears to possesses only one 


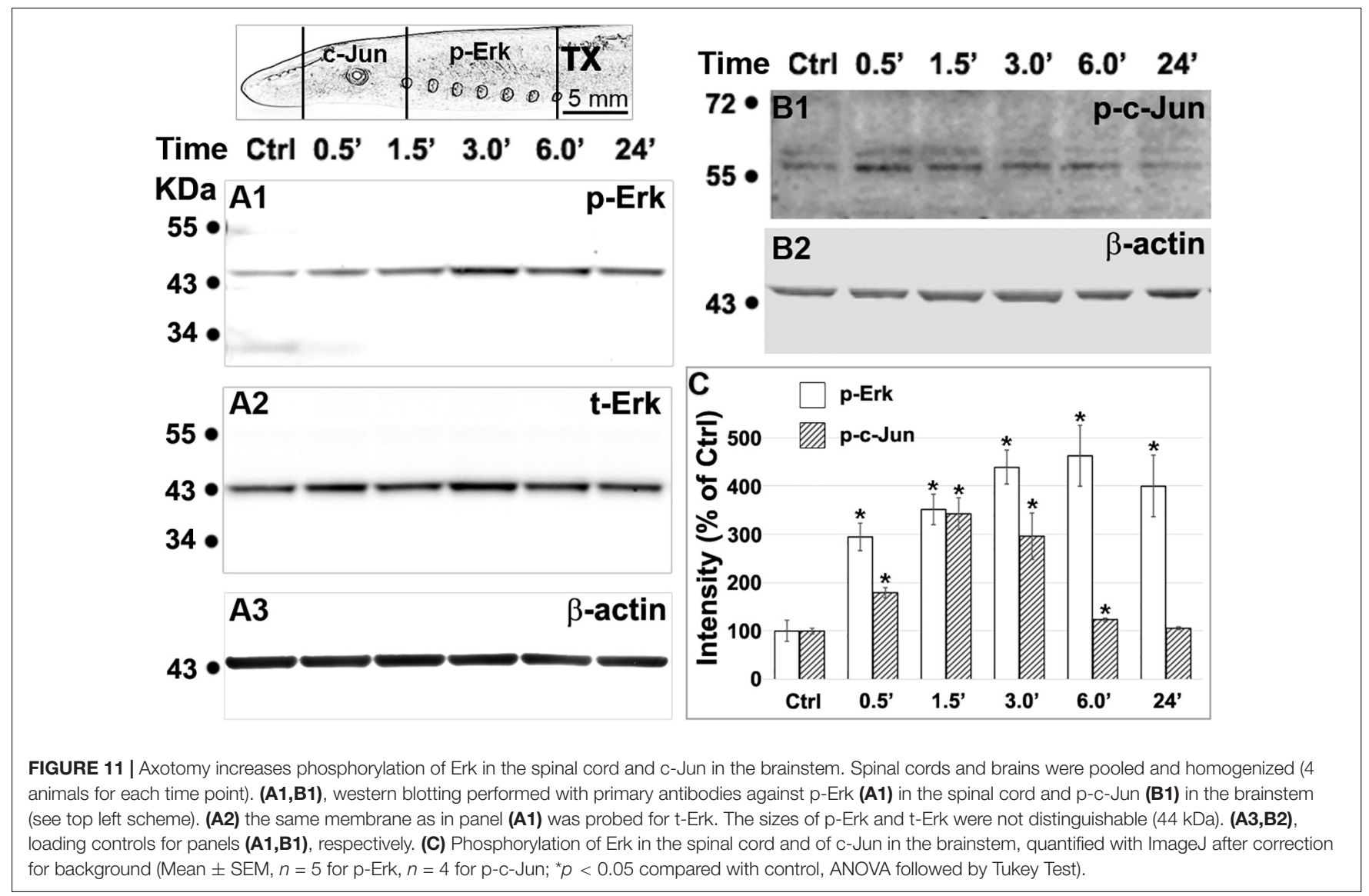

isoform of Erk, Erk2. Because lampreys are considered the closest living relatives to the hypothetical primitive vertebrate ancestor, this is consistent with the suggestion of Buscà et al. $(2015,2016)$ that Erk2 represents the ancestral Erk.

\section{Erk as an Injury Signal}

In the present study, Erk was activated at the TX site within $0.5 \mathrm{~h}$ post-TX, initially distributed diffusely in the cytosol of axons. Western blotting and IHC demonstrated that within $24 \mathrm{~h}, \mathrm{p}$-Erk was being translocated retrogradely in granules. The origins of the p-Erk are not known. Although in spinal cord white matter, levels of t-Erk increased close to the TX, this was much less dramatic and much slower than the increase in p-Erk. We conclude that the increase in t-Erk cannot explain the rapid increase in p-Erk, which must have been due primarily to activation of pre-existing Erk within the injured axon tip. The source of the Erk also is not known. It could derive from translation within the neuron itself, or be released by local cells near the injury, or from the blood. In sections of the TX site, increased p-Erk was found diffusely in both axons and nearby cells. Because Erk is abundant in human erythrocytes (Zennadi et al., 2012), it is possible that Erk released from the blood or injured nearby cells enters the unsealed axons, in a manner similar to that reported recently by this lab for fluorescent tracers (Zhang et al., 2018). After the first $6 \mathrm{~h}$ post-TX, p-Erk levels began to fall at the TX site, whereas they continued to increase at $24 \mathrm{~h}$ in the segments of spinal cord closest to the brain. This is consistent with retrograde transport of p-Erk away from the site of injury, but dephosphorylation at the injury site cannot be excluded.

\section{Erk's Role in Axon Regeneration and Degeneration}

Erk activation is a point of convergence for signaling pathways generated by a variety of axon growth inducers and noxious stimuli. Through phosphorylation of more than 100 different substrates, p-Erk regulates a broad array of cellular functions including proliferation, survival, apoptosis, motility, transcription, metabolism and differentiation (Ramos, 2008), in addition to axon regeneration. Erk's role in neurite extension in response to growth factors is well-recognized. In peripheral nerve, Erk activation has been observed in transected sciatic nerve and ipsilateral DRG. This activation has been ascribed to the actions of a number of neurotrophic factors and cytokines (Sheu et al., 2000; Obata et al., 2003). Growth cone formation following axotomy in DRG or retinal ganglion cell (RGC) cultures (Chierzi et al., 2005) involves activation of Erk. $\mathrm{N}$-cadherin, laminin and basic fibroblast growth factor (b-FGF) can activate Erk in embryonic chick retinal neurons and induce neurite outgrowth, which was inhibited by the Erk inhibitors, PD98059 and U0126 (Perron and Bixby, 1999).

Accumulated evidence suggests that Erk is involved in neuronal death. In cultured primary neurons or neuronal cell 
lines, cell death induced by multiple noxious stimuli can be prevented by pharmacological blockaded of the Erk pathway (Ho et al., 2008; Shirakawa et al., 2008; Chen et al., 2009). Consistent with a role for Erk in promoting cell death, the Erk pathway was implicated in hippocampal damage after traumatic brain injury, and in hyperglycemia-mediated cerebral damage (Zhang et al., 2007; Lu et al., 2008).

The mechanisms by which the Erk pathway might be involved in either axon regeneration or neuronal death are not completely understood. The intensity of Erk pathway activation could underlie the dual effects. Oxidant-induced neuronal death seems to require sustained Erk activation, while transient activation promotes cell survival or regeneration (Subramaniam and Unsicker, 2010). This agrees with our current finding that the heaviest p-Erk staining was found in the large-caliber axons of the ventral column (Figures 5Aad, 6). Their cell bodies in brainstem belong to the most poorly surviving, poorly regenerating identifiable RS neurons (I1, B1, B3, B4, and Mauthner) (Buchanan, 2001). Similarly, in mammals, large DRG neurons preferentially show Erk1/2 activation after sciatic nerve severing (Obata et al., 2003). The intense and persistent activation of p-Erk may be a cause of their selective vulnerability to apoptosis after axotomy. Erk activity can promote either intrinsic or extrinsic apoptotic pathways by induction of mitochondrial cytochrome $c$ release or caspase- 8 activation (Cagnol and Chambard, 2010). This is consistent with a previous report that after spinal cord TX in the lamprey, the extrinsic apoptotic pathway (caspase-8) is activated locally in the giant RS axons and retrogradely translocated to their cell bodies. Intraneuronal caspase- 8 accumulation and cell death in these brainstem neurons was prevented by local treatment with the microtubule stabilizer Taxol (Barreiro-Iglesias et al., 2017). Whether the caspase and Erk pathways converge or are parallel mediators of retrograde neuronal death is not clear, since there exist Erk independent mechanisms by which caspase-mediated apoptotic pathway is activated (Sobrido-Camean and BarreiroIglesias, 2018).

\section{Dynein Colocalizes With p-Erk-Containing Granules, but Vimentin Does Not}

Dynein-related retrograde transport is involved in signaling of axon injury to cell bodies (Rishal and Fainzilber, 2014). Axon injury activates Erk, and other MAPK (JNK, DLK) pathways. This is said to involve local protein translation of multiple constitutive components, including RanBP1, importin $\beta 1$, vimentin, STAT3 and Luman, and is triggered locally by calcium waves (Tasdemir-Yilmaz and Segal, 2016). The locally translated proteins form a complex and are retrogradely transported to the cell bodies in granules via a dynein molecular motor, to activate nuclear transcription factors such as Elk1 (Perlson et al., 2005). In the present study, dynein indeed localized with $\mathrm{p}$-Erk-containing granules.

Vimentin is reported to participate in the complex of retrograde Erk signaling (Perlson et al., 2005). The role of vimentin was clarified by experiments showing that when cleavage products of vimentin complexed with p-Erk they inhibited its dephosphorylation (Perlson et al., 2006). Vimentin is expressed in injured cultured DRG neurons (Willis et al., 2005), and in neurons during Alzheimer disease pathogenesis (Levin et al., 2009). Thus, in mammalian peripheral nerve, locally translated vimentin appears to play a role in the retrograde signaling of axon injury. However, until now, vimentin has not been reported in CNS neurons whose axons have been severed by spinal cord injury. In the present study, IHC showed that normal lamprey CNS axons contain a low background level of vimentin protein, but no intra-axonal vimentin mRNA was found by ISH. In whole-mounted lamprey brain, ISH with a vimentin probe showed widespread staining of small cells, mostly glia (Jin et al., 2016). Spinal cord TX resulted in an increase in vimentin mRNA and protein in axons near the injury site by $6 \mathrm{~h}$ post-TX. This increase in vimentin expression was transient, dropping to normal levels by $24 \mathrm{~h}$ post-TX. In a previous study, vimentin mRNA was not detected in axoplasm microaspirated from growing axon tips (Jin et al., 2016), suggesting that vimentin is not locally translated, but arrives at the injured RS axon tip either by transport from the perikaryon, or by diffusion from the extracellular space after release by injured glial cells. Moreover, vimentin did not colocalize with p-Erk in granules by IHC. The reason for the difference between these findings and those in mammalian peripheral nerve is not known. It may indicate a difference between axons in CNS and the periphery, or a species difference. It also is possible that the difference results from the different techniques employed to study the protein-protein interactions. Our colocalization study using double immunofluorescence IHC might be more precise than immune-coprecipitation performed in peripheral nerves, in which the exact source of vimentin is not established; it could be derived from axons, from Schwann cells, from serum or a combination (Rishal et al., 2010). We conclude tentatively that vimentin is not critical to the retrograde signaling of axon injury by $\mathrm{p}$-Erk.

\section{Activation of c-Jun in the Brain After Spinal Cord Injury}

c-Jun is one component of the activator protein-1 (AP-1) complex. Its typical upstream activators are the c-Jun aminoterminal kinases (JNKs)(Meng and Xia, 2011). The current study showed that spinal cord TX increases levels of $\mathrm{p}$-cJun in the brain, and that this lagged behind the increase in p-Erk in the spinal cord during the first half hour post-TX. However, we did not establish a direct causal link between the retrograde movement of p-Erk and activation of c-Jun. Nor did we establish that the increase in c-Jun activation was specific to the axotomized RS neurons. A functional connection between Erk and c-Jun has been established by mutation studies in fission yeast, in which homologs of mammalian Erk and Jun act in concert to control yeast cell elongation immediately after division (Toda et al., 1991). Activation of c-Jun enhanced axonal outgrowth in rat sensory neurons (Lindwall et al., 2004), an effect (axonal outgrowth) consistent with that obtained with Erk1/2 activation. Inhibition of the ERK1/2 pathway suppressed Elk1 
activation, and recruitment of c-Jun and Fra-2 to their promoters (Adiseshaiah et al., 2008). Moreover, constitutive activation of Erk increases c-Jun transcription and stability, which plays a role in the pathogenesis of human melanomas (Lopez-Bergami et al., 2007).

\section{CONCLUSION}

The present study extends previous findings in mammalian peripheral nerve that the Erk pathway is involved in signaling nerve injury to the axons of a vertebrate CNS. Because Petromyzon marinus occupies a critical phylogenetic position between cephalochordates and gnathostomes, it is likely that the role of the Erk pathway in lamprey spinal axons will prove similar to its role mediating retrograde signals in mammalian CNS, including after spinal cord injury. In the lamprey spinal cord, p-Erk is associated with dynein but, unlike in mammalian peripheral nerve, not vimentin. Whether this is species-specific or a distinction between CNS and peripheral nerve is yet to be determined. Finally, the present findings may have molecular evolutionary significance. They support the notion that the lamprey lacks Erk1 isoforms. All four tested ESTs represent variants of the Erk2 isoform, and may have derived from a single ortholog by genomic duplication. Thus, the Erk1 of other vertebrate species probably evolved from an Erk 2 ancestral protein. Despite these new insights, there are limitations in interpreting static images of a dynamic process. Thus far, we have not obtained sufficient optical resolution to allow us to observe the movement of Erk-containing granules in the living spinal cord. However, this study helps to better understand the role of the Erk pathway in signaling axon injury in the lamprey spinal cord.

\section{REFERENCES}

Adiseshaiah, P., Li, J., Vaz, M., Kalvakolanu, D. V., and Reddy, S. P. (2008). ERK signaling regulates tumor promoter induced c-Jun recruitment at the Fra-1 promoter. Biochem. Biophys. Res. Commun. 371, 304-308. doi: 10.1016/j.bbrc. 2008.04.063

Ambron, R. T., and Walters, E. T. (1996). Priming events and retrograde injury signals. A new perspective on the cellular and molecular biology of nerve regeneration. Mol. Neurobiol. 13, 61-79. doi: 10.1007/bf02740752

Barreiro-Iglesias, A., Sobrido-Camean, D., and Shifman, M. I. (2017). Retrograde activation of the extrinsic apoptotic pathway in spinal-projecting neurons after a complete spinal cord injury in lampreys. Biomed. Res. Int. 2017:5953674.

Boulton, T. G., Nye, S. H., Robbins, D. J., Ip, N. Y., Radziejewska, E., Morgenbesser, S. D., et al. (1991). ERKs: a family of protein-serine/threonine kinases that are activated and tyrosine phosphorylated in response to insulin and NGF. Cell 65, 663-675. doi: 10.1016/0092-8674(91)90098-j

Buchanan, J. T. (2001). Contributions of identifiable neurons and neuron classes to lamprey vertebrate neurobiology. Prog. Neurobiol. 63, 441-466. doi: 10.1016/ s0301-0082(00)00050-2

Buscà, R., Christen, R., Lovern, M., Clifford, A. M., Yue, J. X., Goss, G. G., et al. (2015). ERK1 and ERK2 present functional redundancy in tetrapods despite higher evolution rate of ERK1. BMC Evol Biol 15:179. doi: 10.1186/s12862-0150450-x

\section{DATA AVAILABILITY STATEMENT}

All datasets presented in this study are included in the article/supplementary material.

\section{ETHICS STATEMENT}

The animal study was reviewed and approved by IACUC (protocol \#: 4935) at the Temple University.

\section{AUTHOR CONTRIBUTIONS}

L-QJ did the ISH and carried out the molecular cloning and PCR. L-QJ and BJ did the immunohistochemistry. JH and L-QJ carried out the western blotting. L-QJ and MS carried out the data acquisition and analysis, drafted and prepared the final manuscript, and obtained the funding. All authors had full access to all the data in the study and take full responsibility for the integrity of the data and the accuracy of the data analysis.

\section{FUNDING}

This work was supported by the Shriners Hospitals for Children Grants SHC-85101, SHC85400, and SHC-85220 and NIH grants NS097846 and NS092876.

\section{ACKNOWLEDGMENTS}

We are grateful to Dr. Nicholas Johnson (USGS, Great Lakes Science Center, MI, United States) for generously providing lampreys.

Buscà, R., Pouysségur, J., and Lenormand, P. (2016). ERK1 and ERK2 map kinases: specific roles or functional redundancy? Front. Cell Dev. Biol. 4:53. doi: 10.3389/ fcell.2016.00053

Cagnol, S., and Chambard, J. C. (2010). ERK and cell death: mechanisms of ERKinduced cell death-apoptosis, autophagy and senescence. FEBS J. 277, 2-21. doi: 10.1111/j.1742-4658.2009.07366.x

Cargnello, M., and Roux, P. P. (2011). Activation and function of the MAPKs and their substrates, the MAPK-activated protein kinases. Microbiol. Mol. Biol. Rev. 75, 50-83. doi: 10.1128/mmbr.00031-10

Chen, J., Laramore, C., and Shifman, M. (2015). Triple-labeling wholemount in situ hybridization method for analysis of overlapping gene expression in brain tissue with high level of autofluorescence. J. Cytol. Histol S3:011.

Chen, J., Rusnak, M., Lombroso, P. J., and Sidhu, A. (2009). Dopamine promotes striatal neuronal apoptotic death via ERK signaling cascades. Eur. J. Neurosci. 29, 287-306. doi: 10.1111/j.1460-9568.2008.06 590.x

Cheung, E. C., and Slack, R. S. (2004). Emerging role for ERK as a key regulator of neuronal apoptosis. Sci. STKE 2004:e45.

Chierzi, S., Ratto, G. M., Verma, P., and Fawcett, J. W. (2005). The ability of axons to regenerate their growth cones depends on axonal type and age, and is regulated by calcium, cAMP and ERK. Eur. J. Neurosci. 21, 2051-2062. doi: 10.1111/j.1460-9568.2005.04066.x 
Cochilla, A. J., and Alford, S. (1997). Glutamate receptor-mediated synaptic excitation in axons of the lamprey. J. Physiol. 499(Pt. 2), 443-457. doi: 10.1113/ jphysiol.1997.sp021940

Cruzalegui, F. H., Hardingham, G. E., and Bading, H. (1999). c-Jun functions as a calcium-regulated transcriptional activator in the absence of JNK/SAPK1 activation. EMBO J. 18, 1335-1344. doi: 10.1093/emboj/18.5.1335

Gallo-Oller, G., Ordonez, R., and Dotor, J. (2018). A new background subtraction method for Western blot densitometry band quantification through image analysis software. J. Immunol. Methods 457, 1-5. doi: 10.1016/j.jim.2018.03.004

Hanslik, K. L., Allen, S. R., Harkenrider, T. L., Fogerson, S. M., Guadarrama, E., and Morgan, J. R. (2019). Regenerative capacity in the lamprey spinal cord is not altered after a repeated transection. PLoS One 14:e0204193. doi: 10.1371/ journal.pone.0204193

Hanz, S., and Fainzilber, M. (2006). Retrograde signaling in injured nerve-the axon reaction revisited. J. Neurochem. 99, 13-19. doi: 10.1111/j.1471-4159.2006. 04089.x

Herman, P. E., Papatheodorou, A., Bryant, S. A., Waterbury, C. K. M., Herdy, J. R., Arcese, A. A., et al. (2018). Highly conserved molecular pathways, including Wnt signaling, promote functional recovery from spinal cord injury in lampreys. Sci. Rep. 8:742.

Ho, Y., Samarasinghe, R., Knoch, M. E., Lewis, M., Aizenman, E., and Defranco, D. B. (2008). Selective inhibition of mitogen-activated protein kinase phosphatases by zinc accounts for extracellular signal-regulated kinase 1/2dependent oxidative neuronal cell death. Mol. Pharmacol. 74, 1141-1151. doi: 10.1124/mol.108.049064

Huang, H. T., Sun, Z. G., Liu, H. W., Ma, J. T., and Hu, M. (2017). ERK/MAPK and PI3K/AKT signal channels simultaneously activated in nerve cell and axon after facial nerve injury. Saudi J. Biol. Sci. 24, 1853-1858. doi: 10.1016/j.sjbs.2017.11. 027

Jacobs, A. J., Swain, G. P., Snedeker, J. A., Pijak, D. S., Gladstone, L. J., and Selzer, M. E. (1997). Recovery of neurofilament expression selectively in regenerating reticulospinal neurons. J. Neurosci. 17, 5206-5220. doi: 10.1523/jneurosci.1713-05206.1997

Jin, L. Q., Pennise, C. R., Rodemer, W., Jahn, K. S., and Selzer, M. E. (2016). Protein synthetic machinery and mRNA in regenerating tips of spinal cord axons in lamprey. J. Comp. Neurol. 524, 3614-3640. doi: 10.1002/cne.24020

Jin, L. Q., Zhang, G., Jamison, C. J., Takano, H., Haydon, P. G., and Selzer, M. E. (2009). Axon regeneration in the absence of growth cones; acceleration by cyclic AMP. J. Comp. Neurol. 515, 295-312.

Jin, L. Q., Zhang, G., Pennicooke, B., Laramore, C., and Selzer, M. E. (2011). Multiple neurofilament subunits are present in lamprey CNS. Brain Res. 1370, 16-33. doi: 10.1016/j.brainres.2010.11.037

Kim, E. K., and Choi, E. J. (2010). Pathological roles of MAPK signaling pathways in human diseases. Biochim. Biophys. Acta 1802, 396-405. doi: 10.1016/j.bbadis. 2009.12.009

Kumar, S., Stecher, G., Li, M., Knyaz, C., and Tamura, K. (2018). MEGA X: molecular evolutionary genetics analysis across computing platforms. Mol. Biol. Evol. 35, 1547-1549. doi: 10.1093/molbev/msy096

Lau, B. Y., Fogerson, S. M., Walsh, R. B., and Morgan, J. R. (2013). Cyclic AMP promotes axon regeneration, lesion repair and neuronal survival in lampreys after spinal cord injury. Exp. Neurol. 250, 31-42. doi: 10.1016/j.expneurol.2013. 09.004

Lau, B. Y., Foldes, A. E., Alieva, N. O., Oliphint, P. A., Busch, D. J., and Morgan, J. R. (2011). Increased synapsin expression and neurite sprouting in lamprey brain after spinal cord injury. Exp. Neurol. 228, 283-293. doi: 10.1016/j.expneurol. 2011.02.003

Lee, J. K., Chan, A. F., Luu, S. M., Zhu, Y., Ho, C., Tessier-Lavigne, M., et al. (2009). Reassessment of corticospinal tract regeneration in Nogo-deficient mice. J. Neurosci. 29, 8649-8654. doi: 10.1523/jneurosci.1864-09.2009

Levin, E. C., Acharya, N. K., Sedeyn, J. C., Venkataraman, V., D'andrea, M. R., Wang, H. Y., et al. (2009). Neuronal expression of vimentin in the Alzheimer's disease brain may be part of a generalized dendritic damageresponse mechanism. Brain Res. 1298, 194-207. doi: 10.1016/j.brainres.2009. 08.072

Lindwall, C., Dahlin, L., Lundborg, G., and Kanje, M. (2004). Inhibition of c-Jun phosphorylation reduces axonal outgrowth of adult rat nodose ganglia and dorsal root ganglia sensory neurons. Mol. Cell Neurosci. 27, 267-279. doi: 10.1016/j.mcn.2004.07.001
Lopez-Bergami, P., Huang, C., Goydos, J. S., Yip, D., Bar-Eli, M., Herlyn, M., et al. (2007). Rewired ERK-JNK signaling pathways in melanoma. Cancer Cell 11, 447-460. doi: 10.1016/j.ccr.2007.03.009

Lu, K. T., Cheng, N. C., Wu, C. Y., and Yang, Y. L. (2008). NKCC1mediated traumatic brain injury-induced brain edema and neuron death via Raf/MEK/MAPK cascade. Crit. Care Med. 36, 917-922. doi: 10.1097/ccm. 0b013e31816590c4

McClellan, A. D. (1988). Functional regeneration of descending brainstem command pathways for locomotion demonstrated in the in vitro lamprey CNS. Brain Res. 448, 339-345. doi: 10.1016/0006-8993(88)91273-5

Meng, Q., and Xia, Y. (2011). c-Jun, at the crossroad of the signaling network. Prot. Cell 2, 889-898. doi: 10.1007/s13238-011-1113-3

Merrick, S. E., Pleasure, S. J., Lurie, D. I., Pijak, D. S., Selzer, M. E., and Lee, V. M. (1995). Glial cells of the lamprey nervous system contain keratin-like proteins. J. Comp. Neurol. 355, 199-210. doi: 10.1002/cne.903550204

Murphy, T. H., Worley, P. F., and Baraban, J. M. (1991). L-type voltage-sensitive calcium channels mediate synaptic activation of immediate early genes. Neuron 7, 625-635. doi: 10.1016/0896-6273(91)90375-a

Obata, K., Yamanaka, H., Dai, Y., Tachibana, T., Fukuoka, T., Tokunaga, A., et al. (2003). Differential activation of extracellular signal-regulated protein kinase in primary afferent neurons regulates brain-derived neurotrophic factor expression after peripheral inflammation and nerve injury. J. Neurosci. 23, 4117-4126. doi: 10.1523/jneurosci.23-10-04117.2003

Pancer, Z., Mayer, W. E., Klein, J., and Cooper, M. D. (2004). Prototypic T cell receptor and CD4-like coreceptor are expressed by lymphocytes in the agnathan sea lamprey. Proc. Natl. Acad. Sci. U.S.A. 101, 13273-13278. doi: 10.1073/pnas. 0405529101

Perlson, E., Hanz, S., Ben-Yaakov, K., Segal-Ruder, Y., Seger, R., and Fainzilber, M. (2005). Vimentin-dependent spatial translocation of an activated MAP kinase in injured nerve. Neuron 45, 715-726. doi: 10.1016/j.neuron.2005.01.023

Perlson, E., Michaelevski, I., Kowalsman, N., Ben-Yaakov, K., Shaked, M., Seger, R., et al. (2006). Vimentin binding to phosphorylated Erk sterically hinders enzymatic dephosphorylation of the kinase. J. Mol. Biol. 364, 938-944. doi: 10.1016/j.jmb.2006.09.056

Perron, J. C., and Bixby, J. L. (1999). Distinct neurite outgrowth signaling pathways converge on ERK activation. Mol. Cell Neurosci. 13, 362-378. doi: 10.1006/ mcne.1999.0753

Pfister, K. K., Salata, M. W., Dillman, J. F. III, Vaughan, K. T., Vallee, R. B., Torre, E., et al. (1996). Differential expression and phosphorylation of the $74-\mathrm{kDa}$ intermediate chains of cytoplasmic dynein in cultured neurons and glia. J. Biol. Chem. 271, 1687-1694. doi: 10.1074/jbc.271.3.1687

Photowala, H., Freed, R., and Alford, S. (2005). Location and function of vesicle clusters, active zones and Ca2+ channels in the lamprey presynaptic terminal. J. Physiol. 569, 119-135. doi: 10.1113/jphysiol.2005.091314

Ramos, J. W. (2008). The regulation of extracellular signal-regulated kinase (ERK) in mammalian cells. Int. J. Biochem. Cell Biol. 40, 2707-2719. doi: 10.1016/j. biocel.2008.04.009

Rishal, I., and Fainzilber, M. (2014). Axon-soma communication in neuronal injury. Nat. Rev. Neurosci. 15, 32-42. doi: 10.1038/nrn3609

Rishal, I., Michaelevski, I., Rozenbaum, M., Shinder, V., Medzihradszky, K. F., Burlingame, A. L., et al. (2010). Axoplasm isolation from peripheral nerve. Dev. Neurobiol. 70, 126-133. doi: 10.1002/dneu.20755

Rovainen, C. M. (1967). Physiological and anatomical studies on large neurons of central nervous system of the sea lamprey (Petromyzon marinus). I. Muller and Mauthner cells. J. Neurophysiol. 30, 1000-1023. doi: 10.1152/jn.1967.30.5. 1000

Rovainen, C. M. (1976). Regeneration of Müller and Mauthner axons after spinal transection in larval lampreys. J. Comp. Neurol. 168, 545-554. doi: 10.1002/cne. 901680407

Rovainen, C. M. (1982). Neurophysiology. Cambridge, MA: Academic Press.

Selzer, M. E. (1978). Mechanisms of functional recovery and regeneration after spinal cord transection in larval sea lamprey. J. Physiol. 277, 395-408. doi: 10.1113/jphysiol.1978.sp012280

Selzer, M. E. (1979). The effect of phenytoin on the action potential of a vertebrate spinal neuron. Brain Res. 171, 511-521. doi: 10.1016/0006-8993(79)91055-2

Sheu, J. Y., Kulhanek, D. J., and Eckenstein, F. P. (2000). Differential patterns of ERK and STAT3 phosphorylation after sciatic nerve transection in the rat. Exp. Neurol. 166, 392-402. doi: 10.1006/exnr.2000.7508 
Shifman, M. I., and Selzer, M. E. (2000a). Expression of the netrin receptor UNC-5 in lamprey brain: modulation by spinal cord transection. Neurorehab. Neural Repair. 14, 49-58. doi: 10.1177/154596830001400106

Shifman, M. I., and Selzer, M. E. (2000b). In situ hybridization in wholemounted lamprey spinal cord: localization of netrin mRNA expression. J. Neurosci. Methods 104, 19-25. doi: 10.1016/s0165-0270(00)00316-2

Shifman, M. I., and Selzer, M. E. (2006). Semaphorins and their receptors in lamprey CNS: cloning, phylogenetic analysis, and developmental changes during metamorphosis. J. Comp. Neurol. 497, 115-132. doi: 10.1002/cne.20990

Shifman, M. I., Yumul, R. E., Laramore, C., and Selzer, M. E. (2009). Expression of the repulsive guidance molecule RGM and its receptor neogenin after spinal cord injury in sea lamprey. Exp. Neurol. 217, 242-251. doi: 10.1016/j.expneurol. 2009.02.011

Shirakawa, H., Yamaoka, T., Sanpei, K., Sasaoka, H., Nakagawa, T., and Kaneko, S. (2008). TRPV1 stimulation triggers apoptotic cell death of rat cortical neurons. Biochem. Biophys. Res. Commun. 377, 1211-1215. doi: 10.1016/j.bbrc.2008. 10.152

Smith, J. J., Antonacci, F., Eichler, E. E., and Amemiya, C. T. (2009). Programmed loss of millions of base pairs from a vertebrate genome. Proc. Natl. Acad. Sci. U.S.A. 106, 11212-11217. doi: 10.1073/pnas.0902358106

Smith, J. J., Kuraku, S., Holt, C., Sauka-Spengler, T., Jiang, N., Campbell, M. S., et al. (2013). Sequencing of the sea lamprey (Petromyzon marinus) genome provides insights into vertebrate evolution. Nat. Genet. 45, 415-421.

Smith, J. J., Timoshevskaya, N., Ye, C., Holt, C., Keinath, M. C., Parker, H. J., et al. (2018). The sea lamprey germline genome provides insights into programmed genome rearrangement and vertebrate evolution. Nat. Genet. 50, 270-277. doi: 10.1038/s41588-017-0036-1

Sobrido-Camean, D., and Barreiro-Iglesias, A. (2018). Role of caspase-8 and Fas in cell death after spinal cord injury. Front. Mol. Neurosci. 11:101. doi: 10.1523/ JNEUROSCI.20-18-06879.2000

Subramaniam, S., and Unsicker, K. (2010). ERK and cell death: ERK1/2 in neuronal death. FEBS J. 277, 22-29. doi: 10.1111/j.1742-4658.2009.07367.x

Swain, G. P., Jacobs, A. J., Frei, E., and Selzer, M. E. (1994). A method for in situ hybridization in wholemounted lamprey brain: neurofilament expression in larvae and adults. Exp. Neurol. 126, 256-269. doi: 10.1006/exnr.1994.1063

Tasdemir-Yilmaz, O. E., and Segal, R. A. (2016). There and back again: coordinated transcription, translation and transport in axonal survival and regeneration. Curr. Opin. Neurobiol. 39, 62-68. doi: 10.1016/j.conb.2016.04.006
Toda, T., Shimanuki, M., and Yanagida, M. (1991). Fission yeast genes that confer resistance to staurosporine encode an AP-1-like transcription factor and a protein kinase related to the mammalian ERK1/MAP2 and budding yeast FUS3 and KSS1 kinases. Genes Dev. 5, 60-73. doi: 10.1101/gad.5.1.60

Willis, D., Li, K. W., Zheng, J. Q., Chang, J. H., Smit, A., Kelly, T., et al. (2005). Differential transport and local translation of cytoskeletal, injury-response, and neurodegeneration protein mRNAs in axons. J. Neurosci. 25, 778-791. doi: 10.1523/jneurosci.4235-04.2005

Zennadi, R., Whalen, E. J., Soderblom, E. J., Alexander, S. C., Thompson, J. W., Dubois, L. G., et al. (2012). Erythrocyte plasma membrane-bound ERK1/2 activation promotes ICAM-4-mediated sickle red cell adhesion to endothelium. Blood 119, 1217-1227. doi: 10.1182/blood-2011-03-344440

Zhang, G., Hu, J., Li, S., Huang, L., and Selzer, M. E. (2014). Selective expression of CSPG receptors PTPsigma and LAR in poorly regenerating reticulospinal neurons of lamprey. J. Comp. Neurol. 522, 2209-2229. doi: 10.1002/cne.23529

Zhang, G., Jin, L. Q., Sul, J. Y., Haydon, P. G., and Selzer, M. E. (2005). Live imaging of regenerating lamprey spinal axons. Neurorehab. Neural Repair 19, 46-57. doi: $10.1177 / 1545968305274577$

Zhang, G., Rodemer, W., Lee, T., Hu, J., and Selzer, M. E. (2018). The effect of axon resealing on retrograde neuronal death after spinal cord injury in lamprey. Brain Sci. 8:65. doi: 10.3390/brainsci8040065

Zhang, J. Z., Jing, L., Guo, F. Y., Ma, Y., and Wang, Y. L. (2007). Inhibitory effect of ketamine on phosphorylation of the extracellular signal-regulated kinase $1 / 2$ following brain ischemia and reperfusion in rats with hyperglycemia. Exp. Toxicol. Pathol. 59, 227-235. doi: 10.1016/j.etp.2007.05.002

Zhang, W., and Liu, H. T. (2002). MAPK signal pathways in the regulation of cell proliferation in mammalian cells. Cell Res. 12, 9-18. doi: 10.1038/sj.cr.7290105

Conflict of Interest: The authors declare that the research was conducted in the absence of any commercial or financial relationships that could be construed as a potential conflict of interest.

Copyright (c) $2020 \mathrm{Jin}, \mathrm{John}, \mathrm{Hu}$ and Selzer. This is an open-access article distributed under the terms of the Creative Commons Attribution License (CC BY). The use, distribution or reproduction in other forums is permitted, provided the original author(s) and the copyright owner(s) are credited and that the original publication in this journal is cited, in accordance with accepted academic practice. No use, distribution or reproduction is permitted which does not comply with these terms. 